\title{
Spectroscopic Analyses of Nano-Dispersion Strengthened Transient Liquid Phase Bonds
}

\author{
Kavian Cooke
}

Additional information is available at the end of the chapter

http://dx.doi.org/10.5772/48086

\section{Introduction}

Transient liquid-phase (TLP) bonding is a material joining process that depends on the formation of a liquid at the faying surfaces by an interlayer that melts at a temperature lower than that of the substrate $[1,2,3,4,5]$.

The TLP bonding is distinguished from brazing processes by the isothermal solidification of this liquid. This is accomplished since the interlayer is rich in a melting point depressant (MPD). Upon heating through the eutectic temperature, the interlayer will either melt or react with the base metal to form a liquid. During the hold time above the melting temperature, the melting point depressant (solute) into the base metal (solvent). This resulting solid/liquid interfacial motion via epitaxial growth of the substrate is termed "isothermal solidification." A homogeneous bond between the substrates is formed when the two solid/liquid interfaces meet at the joint centerline marking the end of the isothermal solidification stage.

TLP bonding provides an alternative to fusion welding and has been extensively studied for joining particle-reinforced Al-MMCs [1]. The advantage of using this process is that, reinforcing particles are incorporated into the bond region either by using a particle reinforced insert layer or by the melt-back due to a eutectic reaction between the interlayer and the aluminum alloy [6]. It has been shown in the scientific literature that melt-back can be controlled by using thin interlayer materials. It has also been suggested that heating rate, interlayer composition and thickness are most important in reducing melt-back during TLP bonding. These parameters also determine the width of the liquid phase, removal of surface oxide film and particulate redistribution in the bonded region $[16,7,5]$.

According to Bosco and Zok [8] there exists a critical interlayer thickness at which pore-free bonds are produced. The thickness of the interlayer must exceed that which is consumed 
through solid-state diffusion; otherwise, no liquid is formed at the bonding temperature. This sets a minimal requirement for the interlayer thickness, which can be determined using equation 1:

$$
h_{c}=h_{\eta} C_{\eta}\left(\frac{\rho_{\eta}}{\rho_{i}}\right)^{2}
$$

Where, $2 h_{\eta}$ is the total thickness of the reaction layer formed at the interlayer/MMC interface when the eutectic temperature is reached, $C_{\eta}$ is the mass fraction of $\mathrm{Ni}$ in the reaction layer. The mass densities of the reaction layer and the Ni interlayer are $\rho_{\eta}$ and $\rho_{N i}$ respectively. On the other hand, Li et al. [5] suggested that a maximum thickness exists that minimizes particle segregation and maximises joint strength. The composition of the interlayer has also been shown by Eagar and McDonald [9] to be equally as important as the interlayer thickness. In the published literature, it has been shown that pure metal interlayers such as nickel $[10,11]$, silver $[12,13]$ and copper $[13,15]$ can react with the metal surface by means of eutectic or peritectic reaction to displace surface oxides and regulates the bonding temperature. In joints made using these pure interlayers, the existing problems can be summarized as: parent metal dissolution particulate segregation [13, 14,15], void formation in particle segregated region [12] and low strength micro-bonds at particle-metal interfaces resulting from the poor wettability of molten interlayer on ceramic reinforcement $[12,16]$. Particle segregation has been shown by Stefanescu et al $[17,18]$ to be promoted by the slow movement of the solid-liquid interface during isothermal solidification. Li et al. [5] showed that during TLP bonding of Al-MMCs containing particulate reinforcements with diameters less than $30 \mu \mathrm{m}$, particle segregation to the interface occurred when a copper foil thickness between 5 and $15 \mu \mathrm{m}$ was used. Earlier research used alloyed interlayers such as; $\mathrm{Zn}-\mathrm{Al}$, $\mathrm{Cu}-\mathrm{Al}$ and $\mathrm{Cu} / \mathrm{Ni} / \mathrm{Cu}$ systems to decrease bonding temperature in air and to prevent particulate segregation [19]. While composite interlayers such as $\mathrm{Al}-\mathrm{Si}-\mathrm{W}$ mixed powder and $\mathrm{Al}-\mathrm{Si}-\mathrm{Ti}-\mathrm{SiC}$ mixed powder were used to improve the densification of a thick reaction layer which formed at the joint. This layer was reinforced with a metallic phase and a ceramic phase [20].

Recent studies into joining Al-MMCs have focused on decreasing bonding temperature by using Sn-based interlayers reinforced with silicon carbide. The results show that joint strength of $\mathrm{Al} 6061+25 \%\left(\mathrm{Al}_{2} \mathrm{O}_{3}\right) \mathrm{p}$ improved by approximately $100 \%$ when compared to unreinforced Sn-based joints formed by ultrasonic assisted soldering [21]. Yan et al. [22] developed a SiC particle reinforced Zn-based filler which was used to join SiCp/A356 composite. The results indicated that with the use of ultrasonic vibration suitable particle distribution and reduced void formation were achieved. Cooke et al. [23, 24] used an electrodeposited $\mathrm{Ni}-\mathrm{Al}_{2} \mathrm{O}_{3}$ nano-composite coatings to join Al-6061 MMC. The results showed that the use of $\mathrm{Ni}_{-} \mathrm{Al}_{2} \mathrm{O}_{3}$ nano-composite coatings can be used successfully to increase joint strength when compared to TLP bond produced using pure Ni-coating. The results also showed that coating thickness of $5 \mu \mathrm{m}$ can be used to control particle segregation during TLP bonding of Al-6061 MMC 
In order to study the kinetics of TLP bonding, techniques such as wavelength dispersive spectroscopy, energy dispersive spectroscopy and x-ray diffraction spectroscopy are normally used, since the compositional changes across the joint region is the mechanism by which the process progresses to completion. In previous studies EDS, WDS and XRD has been used extensive for studying materials due in part to the flexibility that the techniques afford. In most papers, a choice is made between the two processes depending on the information that is required. The difference between these processes are that, the energydispersive (ED) type records $\mathrm{X}$-rays of all energies effectively simultaneously and produces an output in the form of a plot of intensity versus X-ray photon energy. The detector consists of one of several types of device producing output pulses proportional in height to the photon energy. Whereas the wavelength-dispersive (WD) type makes use of Bragg reflection by a crystal, and operates in 'serial' mode, the spectrometer being 'tuned' to only one wavelength at a time. Several crystals of different interplanar spacing are needed in order to cover the required wavelength range. Spectral resolution is better than for the ED type, but the latter is faster and more convenient to use. X-ray spectrometers attached to SEMs are usually of the ED type, though sometimes a single multi-crystal WD. This chapter examines the application of spectroscopic analyses such as EDS, WDS and XRD to the evaluation of nanostructure TLP bonds using $\mathrm{Ni}-\mathrm{Al}_{2} \mathrm{O}_{3}$ nano-composite thin film as a filler material during TLP bonding of Al-6061MMC. The effects of process parameters on the mechanical and microstructural microstructural changes in the joint region will also be studied.

\subsection{Spectroscopic analysis techniques}

The characterization of materials using spectroscopic techniques such as energy dispersive spectroscopy or x-ray diffraction spectroscopy techniques is dependent on the generation of a beam of electrons which interacts with the sample to be analyzed. When electrons strike a anode with sufficient energy, X-rays are produced. This process is typically accomplished using a sealed $\mathrm{x}$-ray tube, which consists of a metal target and a tungsten metal filament, which can be heated by passing a current through it resulting in the "boiling off" of electrons from the hot tungsten metal surface. These "hot" electrons are accelerated from the tungsten filament to the metal target by an applied voltage The collision between these energetic electrons and electrons in the target atoms results in electron from target atoms being excited out of their core-level orbitals, placing the atom in a short-lived excited state. The atom returns to its ground state by having electrons from lower binding energy levels make transitions to the empty core levels. The difference in energy between these lower and higher binding energy levels is radiated in the form of X-rays. This process results in the production of characteristic X-rays. X-rays are generated when the primary beam ejects an inner shell electron thus exciting the atom. As an electron from the outer shell drops in to fill the vacancy and de-excite the atom it must give off energy. This energy is specific to each individual element in the periodic table and is also specific to what particular electron dropped in to fill the vacancy. The conversion between energy, frequency, and wavelength is the well-known de Broglie 
relationship: $\mathrm{E}=\mathrm{h} v=\mathrm{hc} / \lambda$, where $v$ is the frequency, $\mathrm{h}$ is Planck's constant $\left(6.62 \times 10^{-34}\right.$ joule-second), $\mathrm{c}$ is the speed of light $\left(2.998 \times 10^{8} \mathrm{~m} / \mathrm{sec}\right)$, and $\lambda$ is the wavelength of the radiation (in $\mathrm{m}$ ). Based on this relationship, two distinct types of $\mathrm{x}$-ray detector systems are used. These two types of detector systems are called Energy-Dispersive x-ray Spectrometry (EDS) and Wavelength-Dispersive x-ray Spectrometry (WDS).

EDS spectrometer are most frequently attached to electron column instruments such as SEM or (EPMA). As the name implies is a method of x-ray spectroscopy by which x-rays emitted from a sample are sorted out and analyzed based on the difference in their energy level. An EDS system consists of a source of high-radiation; a sample, a solid-state detector (usually from lithium-drifted silicon $(\mathrm{Si}(\mathrm{Li}))$; and a signal processing electronics. When the sample atoms are ionized by a high-energy radiation, they emit characteristic x-rays. X-rays that enter the $\mathrm{Si}(\mathrm{Li})$ detector are converted into signals (charge pulses) that can be processed by the electronics into an $x$-ray energy histogram. This $x$-ray spectrum consists of a series of peaks representative of the type and relative amount of each element in the sample. The number of counts in each peak can be further converted to elemental weight concentration either by comparison standards or standardless calculations. In general, three principal types of data can be generated using an EDS detector: (i) x-ray dot maps or images of the sample using elemental distribution as a contrast mechanism, (ii) line scan data or elemental concentration variation across a given region, and (iii) overall chemical composition, both qualitative and quantitatively.

As the name implies, WDS is a detection system by which $x$-rays emitted from the sample are sorted out and analyzed based on differing wavelength $(\lambda)$ in the WDS, or crystal spectrometry. As in EDS or imaging mode, the beam rasters the sample generating $x$-rays of which a small portion enters the spectrometer. As the fluorescent $x$-rays strike the analyzing crystal, they will either past through the crystal, be absorbed, be scattered, or be diffracted. Those which satisfy Bragg's Law; $n \lambda=2 d \operatorname{Sin} \theta$.

(where $\mathrm{n}=$ an integer, $d=$ the interplanar spacing of the crystal, $\theta=$ the angle of incidence, and $\lambda=x$-ray wavelength) will be diffracted and detected by a proportional counter. The signal from this detector is amplified, converted to standard pulse size in the single channel analyzer and counted with a scalar or displayed as rate vs time on rate meter. By varying the positioning crystal one changes the wavelength that will satisfy Bragg's Law. Therefore one can sequentially analyze different elements. By automating crystal movements one can dramatically speed up the analysis time. Typically the WDS analysis is used to gain the same type of information that the EDS is used for, qualitative and quantitative and quantitative information, line scan and dot maps for elemental distribution.

\subsection{X-ray diffraction}

X-ray diffraction (XRD) is another quantitative spectroscopic technique which reveals information about the crystal structure, chemical composition, and physical properties of materials and thin films. These techniques are based on observing the scattered intensity of an X-ray beam hitting a sample as a function of incident and scattered angle, polarization, 
and wavelength or energy. Similar to the EDS and WDS techniques discussed above X-ray diffraction is dependent on Bragg equation, which describes the condition for diffraction to occur in terms of the wavelength of the x-radiation $(\lambda)$, the interplanar (" $d$ ") spacings of the crystal, and the angle of incidence of the radiation with respect to the crystal planes $(\theta)$. As the spacing between atoms is on the same order as X-ray wavelengths crystals can diffract the radiation when the diffracted beams are in-phase.

When the incident beam satisfies the Bragg condition, a set of planes forms a cone of diffracted radiation at an angle $q$ to the sample. Since the cone of $X$-rays intersects the flat photographic filmstrip in two arcs equally spaced from the direct $X$-ray beam, two curved lines will be recorded on the photographic film. The distance of the lines from the center can be used to determine the angle $\mathrm{q}$, which can then be used to determine the interplanar " $\mathrm{d}$ " spacing. X-ray powder diffractometers record all reflections using a scintillation detector (in counts per second of X-rays). The pattern of diffracted X-rays is unique for a particular structure type and can be used as a "fingerprint" to identify the structure type. Different minerals have different structure types, thus X-ray diffraction is an ideal tool for identifying different minerals.

\section{Electrodeposition of the nano-composite $\mathrm{Ni} / \mathrm{Al}_{2} \mathrm{O}_{3}$ coating}

Composite coatings can be produced by co-deposition of fine inert particles into a metal matrix from an electrolytic or an electroless bath. This technique is getting interesting due to its ability to produce films with excellent mechanical properties such as wear resistance, corrosion resistance, and lubrication.

The preparation of a composite coating is done in two steps. First, an effective dispersion of fine inert particles is produced in the electrolyte. Next, the preparation of the composite coating is made by the manipulation of electrochemical conditions. An effective dispersion of inert particles in the electrolyte promotes the adsorption opportunity of inert particles on the cathode. It causes a higher volume content of inert particles in the composite coating. The mechanical properties of the composite coating are also promoted with the enhancement of the volume content of inert particles in the coating. In electrodeposited composites, the particles to be dispersed in the metal matrix are maintained in suspension in the bath by agitation and they become incorporated in the coating by a process known as electrophoresis.

A number of coating parameters were studied to determine the effect of each on the coating thickness: $\mathrm{pH}$ of the electrolyte, current density, electrolyte temperature, agitation frequency and deposition time [33]. Samples were coated for time intervals of 2, 4, 6, 8, 10, 15, 20 and 30 minutes. After electrodeposition, coating thickness was determined using a light microscope. Figure 1(b) shows the relationship between coating thickness and deposition time when; the current density was set to $1.0 \mathrm{~A} / \mathrm{dm}^{2}, \mathrm{pH} 3.0$, agitation frequency of $300 \mathrm{rpm}$ and an electrolyte temperature of $50^{\circ} \mathrm{C}$ [25]. It was found that the coating thickness increased with increasing deposition time, in keeping with Faraday's law governing electrode reactions during electrolysis [26]. 


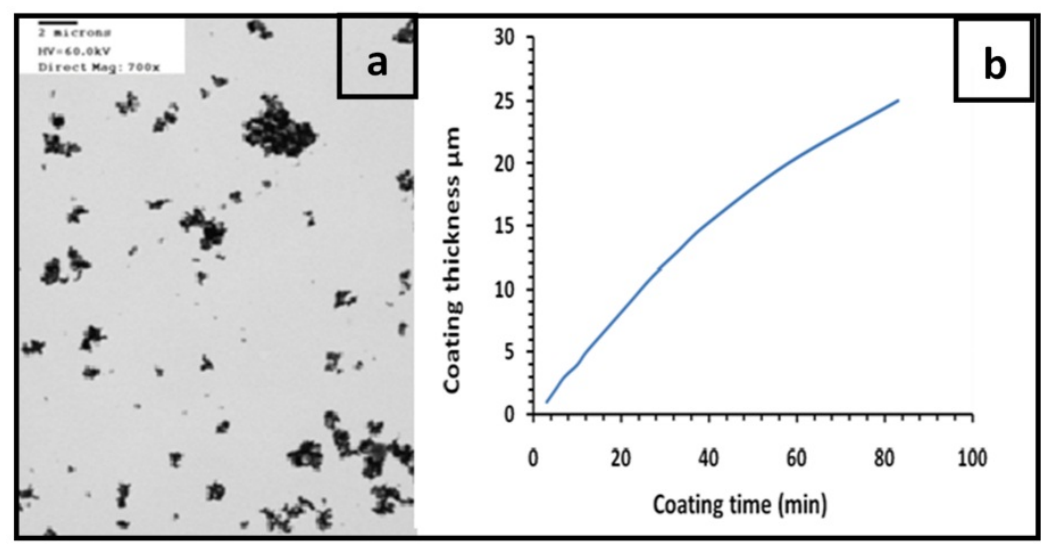

Figure 1. (a) TEM image of as-received nano-sized $\mathrm{Al}_{2} \mathrm{O}_{3}$ powder (b) Coating thickness as a function of electrodeposition time at $1.0 \mathrm{~A} / \mathrm{dm}^{2}$ and $50{ }^{\circ} \mathrm{C}$ [33].

In this study, $\mathrm{Al}-6061 / \mathrm{Al}_{2} \mathrm{O}_{3} \mathrm{p}$ samples of dimensions $10 \times 10 \times 5 \mathrm{~mm}$ were prepared to 800 grit abrasive paper and polished to $1 \mu \mathrm{m}$ diamond suspension after which they were cleaned in an acetone bath. Acid pickling took place in a solution of $15 \mathrm{wt} . \% \mathrm{HNO}_{3}$ and 2 wt. $\% \mathrm{HF}$ at $50{ }^{\circ} \mathrm{C}$ for 2 minutes and then rinsed in distilled water. The plating solution was prepared by dissolving: $250 \mathrm{~g} / \mathrm{L} \mathrm{NiSO}_{4} 6 \mathrm{H}_{2} \mathrm{O}, 45 \mathrm{~g} / \mathrm{L} \mathrm{NiCl} 2.6 \mathrm{H}_{2} \mathrm{O}, 35 \mathrm{~g} / \mathrm{L} \mathrm{H} \mathrm{HBO}_{3}$ and $1 \mathrm{~g} / \mathrm{L}$ Saccharin in distilled water. The Ni- $\mathrm{Al}_{2} \mathrm{O}_{3}$ composite coating was produced by adding $50 \mathrm{~g} / \mathrm{L}$ of ceramic particles to a separately to the nickel bath. The particles were thoroughly mixed into the solution for two hours and kept in suspension in the bath with a magnetic stirrer rotating at $300 \mathrm{rpm}$. The coating solution was maintained at a temperature of $50^{\circ} \mathrm{C}$ and $\mathrm{pH}$ of 3.0 [33]. The thickness of $\mathrm{Ni}-\mathrm{Al}_{2} \mathrm{O}_{3} \mathrm{p}$ coatings were controlled by the current density and plating time. The actual amount of $\mathrm{Ni}-\mathrm{Al}_{2} \mathrm{O}_{3} \mathrm{p}$ electroplated onto a surface was determined by the weight gain after the plating process. The coating thickness was calculated by using the equations 2 and 3 :

$$
\rho_{C}=\frac{\text { mass of coating }}{\text { Area } x \text { thickness }}=\frac{m}{A x t}
$$

The density of the composite coating $\left(\rho_{C}\right)$ can be calculated by using Equation 3 (rule of mixtures) where $x_{v}$ is the volume fraction of alumina particles in the $\mathrm{Ni}-\mathrm{Al}_{2} \mathrm{O}_{3}$ coating.

$$
\rho_{\mathrm{C}}=\rho_{\mathrm{Al}_{2} \mathrm{O}_{3}} x_{v}+\rho_{\mathrm{Ni}}\left(1-x_{v}\right)
$$

\subsection{Spectroscopic analysis of the film structure and composition}

Wavelength dispersive spectroscopic (WDS) and X-ray diffraction (XRD) spectroscopic analyses of the coatings deposited were used to evaluate the distribution of the dispersion particles. Figure 2 shows an SEM micrographs of the coating produced by the coelectrodeposition of $\mathrm{Ni}+18 \mathrm{vol} \%$ (nano- $\left.\mathrm{Al}_{2} \mathrm{O}_{3}\right)$ p. Examination of the coatings using a light 
microscope revealed the absence of surface defects and interfacial void, however $\mathrm{Al}_{2} \mathrm{O}_{3}$ particle clusters were present in the coating. This was attributed to particle clustering in the powder prior to the coating process as indicated by the TEM image of the as-received $\mathrm{Al}_{2} \mathrm{O}_{3}$ powder shown in Figure 1(a). The volume fraction of $\mathrm{Al}_{2} \mathrm{O}_{3}$ present in the coating was studied by digital x-ray mapping and these results are shown in Figure 3. From Figure $3 b$ and $3 c$, the areas which contains a high concentration of $\mathrm{Al}_{2} \mathrm{O}_{3}$ are easily identify and corresponds to $\mathrm{Al}$ and $\mathrm{O}$ which would confirm the compound to be $\mathrm{Al}_{2} \mathrm{O}_{3}$ since the base coating is $\mathrm{Ni}$.

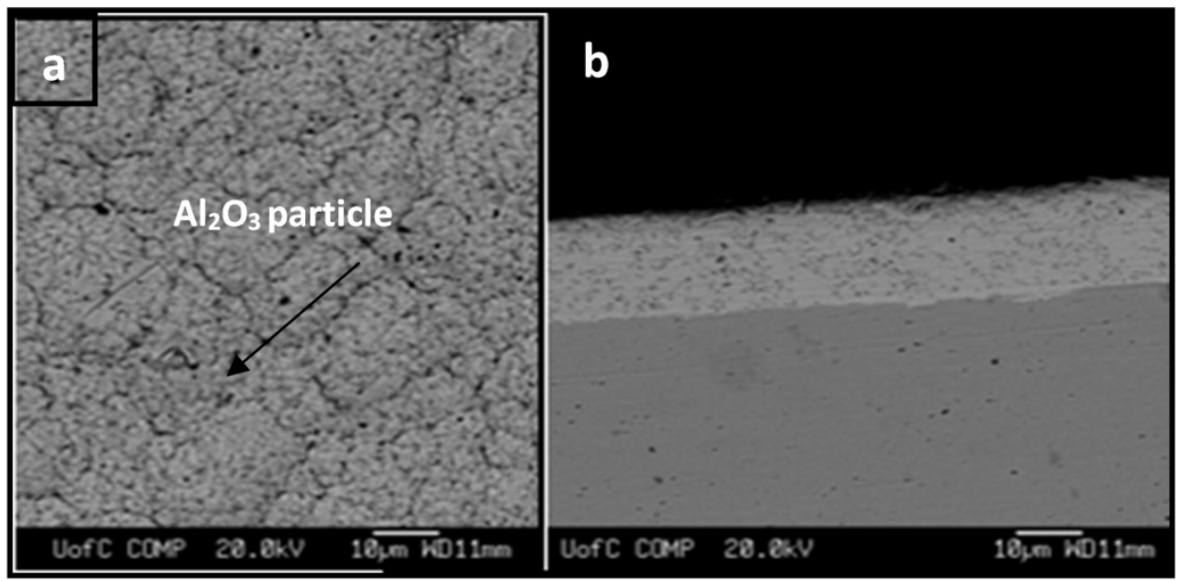

Figure 2. (a) Surface of the $\mathrm{Ni}-\mathrm{Al}_{2} \mathrm{O}_{3}$ coating and (b) Cross-section of the $\mathrm{Ni}-\mathrm{Al}_{2} \mathrm{O}_{3}$ coating produced by electrodeposition [33].

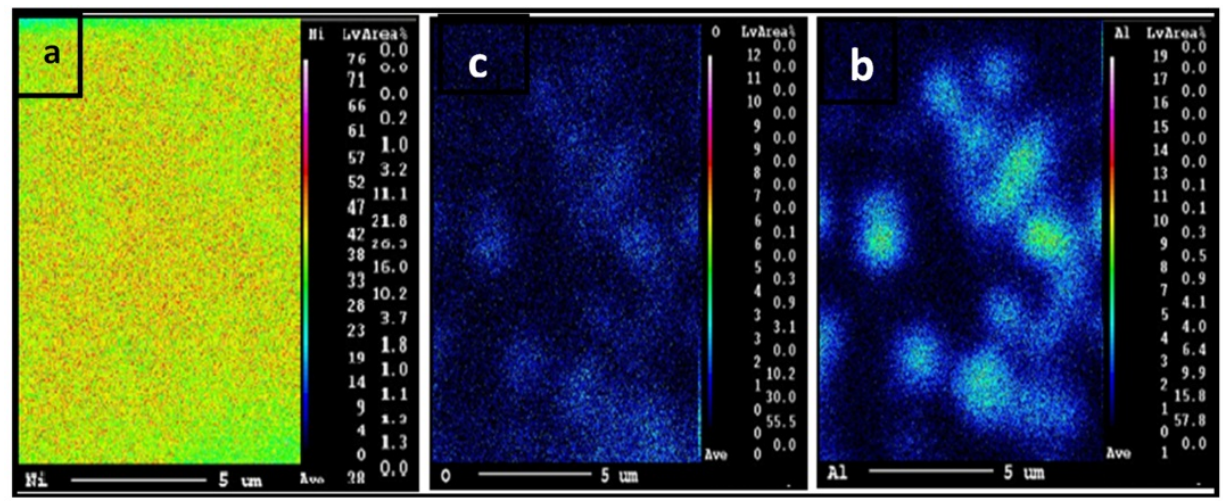

Figure 3. X-ray digital composition maps taken from the $\mathrm{Ni}-\mathrm{Al}_{2} \mathrm{O}_{3}$ coating surface for; (a) $\mathrm{Ni}$, (b) $\mathrm{O}$ and (c) $\mathrm{Al}[33]$.

\section{Fundamentals of transient liquid phase bonding}

TLP bonding requires that the base metal surfaces are brought into intimate contact with a thin interlayer placed between the bonding surfaces. The interlayer can be added in the form 
of a thin foil, powder or coating $[27,28]$ which is tailored to melt by eutectic or peritectic reaction with the base metal. The liquid filler metal wets the base metal surface and is then drawn into the joint by capillary action until the volume between components to be joined is completely filled.

The driving force of TLP bonding is diffusion. A process which can be described by Fick's first and second laws. The first law describes diffusion under steady-state conditions and is given by equation 4 :

$$
J=-D \frac{\partial C}{\partial x}
$$

Fick's second law describes a non-steady state diffusion in which the concentration gradient changes with time and can be expressed as shown in equation 5 :

$$
\frac{\partial C}{\partial t}=D \frac{\partial^{2} C}{\partial x^{2}}
$$

Equation 6 shows a general solution for Equation-5 using separation of variables is [29]:

$$
C(x, t)=\frac{1}{2 \sqrt{D \pi t}} \int_{-\infty}^{+\infty} f(\xi) e^{\left(\frac{\xi-x)}{4 D t}\right.} d \xi
$$

Where the error function solution for equation 6 is shown in equation 7 :

$$
C(x, t)=\frac{C_{0}}{2}\left[\operatorname{erf}\left(\frac{x-x_{1}}{\sqrt{4 D t}}\right)-\operatorname{erf}\left(\frac{x-x_{2}}{\sqrt{4 D t}}\right)\right]
$$

If the following boundary conditions are applied to Equation-7, the concentration as a function of time can be calculated using Equation-8:

$$
\begin{aligned}
& C(x, 0)=\left\{\begin{array}{ll}
C_{0} & (x>0) \\
0 & (0<x)
\end{array} \text { and } C(x, 0)= \begin{cases}C_{0} & x=+\infty \\
0 & x=-\infty\end{cases} \right. \\
& C(x, t)=C_{0}\left(1-\operatorname{erf}\left(\frac{x}{\sqrt{4 D t}}\right)+\operatorname{erf}\left(\frac{k x}{\sqrt{4 D t}}\right)\right)
\end{aligned}
$$

TLP bonding can be conducted by one of two distinct methods. Method-I employs a pure interlayer which forms a liquid through eutectic reaction with the base metal and Method-II employs an interlayer with a liquidus temperature near the bonding temperature [2]. Method-II is most commonly used as it reduces the overall process time by decreasing the volume of solute to be diffused from the interface before the liquid is formed. On the other hand, method-I can be considered to be more effective in TLP bonding as the eutectic reaction is able to displace surface oxides during bonding. TLP bonding process was first divided into five discrete stages by Duvall et al. [30]. These stages were: heating, melting, 
dissolution of the base-metal, isothermal solidification and homogenization of the excess solute at the bond-line. Zhou later condensed the TLP process to three stages: base-metal dissolution, isothermal solidification and homogenization [7]. In later work by MacDonald and Eager [9] the second and third stage described by Duvall were combined to give four stages; heating, melting and parent metal dissolution, isothermal solidification and homogenization. Zhou [7] reclassified his earlier work to include a heating stage. The second stage was also expanded to be dissolution and widening.

\section{Effect of bonding variables on microstructural evolution}

This section investigates the effects of bonding variables on the chemical and microstructural homogeneity across the joint region. Factors affecting TLP bonding are; bonding temperature, bonding time, contact pressure and interlayer thickness and composition. Contact pressure can also affect the strength of the bond produced and this has been reported extensive in the scientific literature. However in this work, when bonding pressure increased beyond $0.1 \mathrm{MPa}$ the result is rapid creep failure during the bonding process. Therefore the bonding pressure was held constant at $0.01 \mathrm{MPa}$. The effects of these parameters were evaluated using WDS and XRD to study the change in chemical composition across the joint region as a function of bonding variable.

\subsection{Effect of bonding time on joint properties}

Wavelength dispersive spectroscopic analyses of joints bonded at $600^{\circ} \mathrm{C}$ using a $5 \mu \mathrm{m}$ thick Ni$\mathrm{Al}_{2} \mathrm{O}_{3}$ coating as the interlayer as a function of bonding time as shown in Table 1. For joints bonded for 1 minute a large concentration of Ni remained at the interface after bonding. However, when the bonding time was increased to 30 minutes resulted in the elimination of the interface and an increase in the grain size within the joint. This disrupts the band of segregated particles at the interface (see Figure 4) and chemically homogenized the joint zone.



Figure 4. Light micrographs of joint bonded with $5 \mu \mathrm{m}$ thick $\mathrm{Ni}-\mathrm{Al}_{2} \mathrm{O}_{3}$ coating for: (a) 1 min (b) $30 \mathrm{~min}$ [23]. 
The segregation of particles was accredited to the pushing of micro- $\mathrm{Al}_{2} \mathrm{O}_{3}$ particles by the solidifying liquid-solid interface. Stefanescu [18] showed that particle pushing can be assumed to be a steady-state condition under which the interface velocity can be assumed to be equal the rate of isothermal solidification. Li et al. [5] suggested that the segregation tendency is dependent on the relationship between the liquid film width produced at the bonding temperature, particle diameter and inter-particle spacing. When the liquid film width is large enough that sufficient particulate material is contained in the melt, particles will be pushed ahead of the solidifying liquid-solid interface resulting in particle segregation at the bond-line. However if the liquid film width is less than some critical value, segregation should not occur.

In the reported studies on transient liquid phase diffusion bonding of Al-MMCs it was shown that the width of the segregated zone at the joint center increased with increasing bonding time. The opposite of this relationship was seen when using the $\mathrm{Ni}-\mathrm{Al}_{2} \mathrm{O}_{3}$ coating. As the bonding time increased, the width of the segregated region decrease. This can be attributed to the heterogeneous nucleation of grains within the joint zone during solidification and this lead to grain refining at the joint. A high resolution SEM micrograph shown in Figure 5 revealed the presence of a nano-sized alumina particle at the center of a grain. EDX spectra of the particle showed $\mathrm{Al}$ and $\mathrm{O}$ in high concentrations with traces of $\mathrm{Mg}$ $[23,24,33]$. Comparing Gibbs free energy of formation at the bonding temperature for $\mathrm{MgO}$ $(-1195 \mathrm{~kJ} / \mathrm{mol})$ and $\mathrm{Al}_{2} \mathrm{O}_{3}(-985 \mathrm{~kJ} / \mathrm{mol})$ it is found that $\mathrm{Al}_{2} \mathrm{O}_{3}$ is unstable in the presence of $\mathrm{Mg}$ hence it is like that some of the nano-size $\mathrm{Al}_{2} \mathrm{O}_{3}$ will decomposed to form $\mathrm{MgAl}_{2} \mathrm{O}_{4}$ compound. WDS analysis across the joint zone as a function of bonding time indicated that the $\mathrm{Ni}$ volume at the joint center varied between $3.122 \mathrm{wt} \%$ after 1 minute and $0.37 \mathrm{wt} \%$ after 30 minutes bonding time (see Table 1 ).

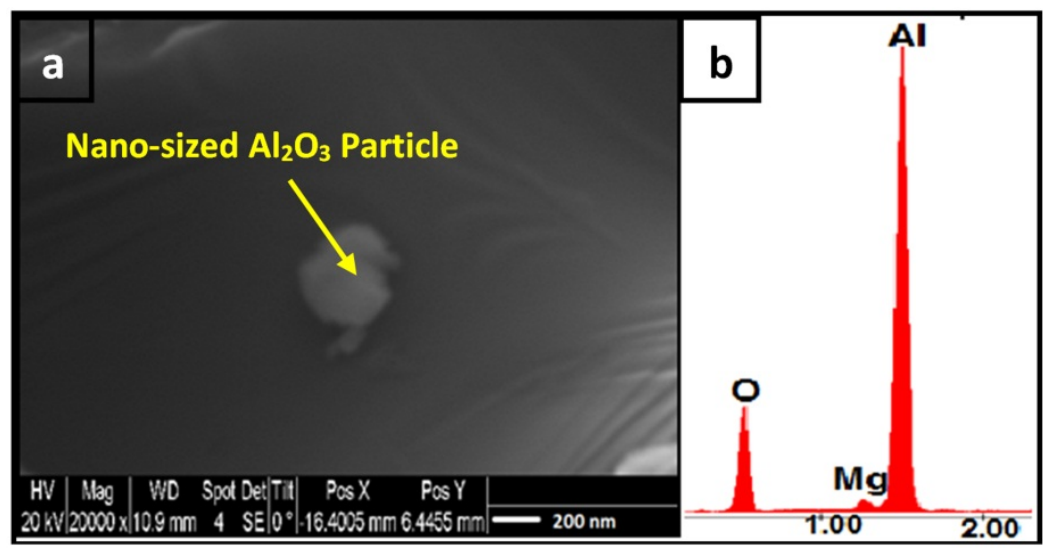

Figure 5. (a) SEM image of nano-particle present in the center of a grain (b) EDS analysis of nano- $\mathrm{Al}_{2} \mathrm{O}_{3}$ particle [23] 


\begin{tabular}{|c|c|c|c|c|c|c|}
\hline Time $(\mathrm{min})$ & $\mathrm{Fe} / \mathrm{wt} \%$ & $\mathrm{Ni} / \mathrm{wt} \%$ & $\mathrm{Si} / \mathrm{wt} \%$ & $\mathrm{Mg} / \mathrm{wt} \%$ & $\mathrm{Cu} / \mathrm{wt} \%$ & $\mathrm{Al} / \mathrm{wt} \%$ \\
\hline 1 & 0.399 & 3.122 & 0.633 & 0.379 & 0.586 & 93.635 \\
\hline 5 & 0.677 & 0.849 & 0.863 & 1.047 & 0.71 & 79.375 \\
\hline 10 & 0.049 & 0.071 & 0.211 & 0.676 & 0.162 & 98.598 \\
\hline 30 & 0.028 & 0.037 & 0.091 & 0.458 & 0.087 & 99.153 \\
\hline
\end{tabular}

Table 1. WDS analysis of joints made at $600^{\circ} \mathrm{C}$ as a function of bonding time

\subsection{Effect of temperature on joint properties}

Wavelength dispersive spectroscopic analyses of the joint as a function of bonding temperature indicated that the Ni concentration at the interface decreased from $4.65 \mathrm{wt} \%$ to $0.19 \mathrm{wt} \%$ as the bonding temperature is increased from 570 to $620^{\circ} \mathrm{C}$ (see Table 2). This was attributed to an increase in the diffusivity of $\mathrm{Ni}$ from the interface into the base metal as the temperature increased. A review of the scientific literature shows that the diffusivity of $\mathrm{Ni}$ increased from $D_{570}=4.69 \times 10^{-13} \mathrm{~m}^{2} / \mathrm{s}$ to $D_{620}=1.58 \times 10^{-12} \mathrm{~m}^{2} / \mathrm{s}$ when the bonding temperature was increased from 570 to $620^{\circ} \mathrm{C}[10,31]$.

A study of the joint microstructure for a bond made at $570^{\circ} \mathrm{C}$ revealed the segregation of $\mathrm{Al}_{2} \mathrm{O}_{3}$ particles to the bond-line as shown in Figure 6(a). When the bonding temperature was increased to $590^{\circ} \mathrm{C}$ the width of the particle segregated zone within the joint decreased to approximately $150 \mu \mathrm{m}$ as shown in Figure 6 (b). Further increase in bonding temperature to $600^{\circ} \mathrm{C}$ also resulted in a reduction of the width of the segregated zone. A similar result was obtained when the bonding temperature was increased to $620^{\circ} \mathrm{C}$ (see Figure $6 \mathrm{~d}$ ). This observation was consistent with earlier literature, which suggested that the use of thin interlayers during bonding can help to control the degree of particle segregation taking place within the joint [5]. The micrographs indicate that the width of the particle segregated zone decreases with increasing bonding temperature. This can be attributed to particle pushing by the primary $\alpha$-phase during solidification as shown in section $4.1[17,18]$.

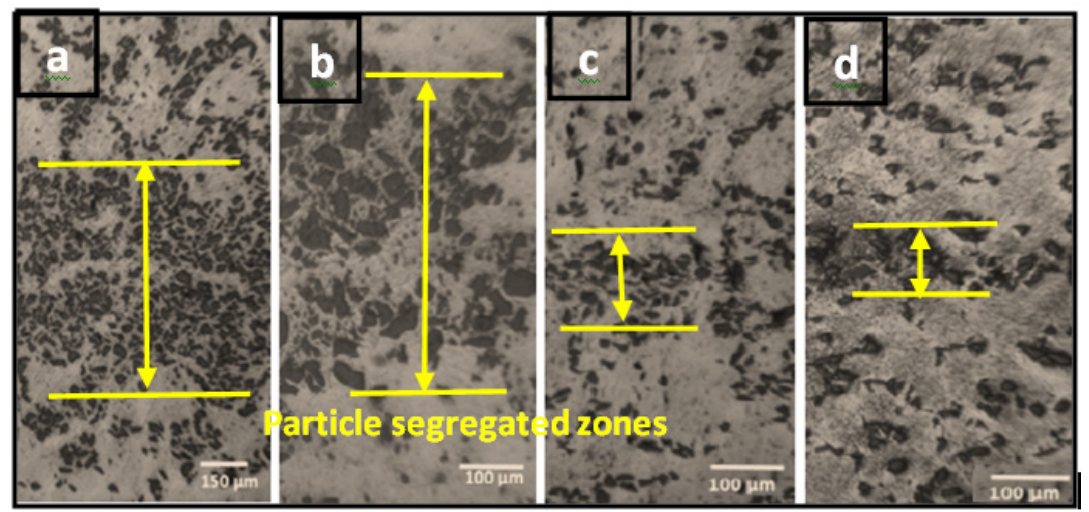

Figure 6. Light micrographs of joint region for bonding temperatures of (a) $570^{\circ} \mathrm{C}$ and (b) $590^{\circ} \mathrm{C}$ (c) $600^{\circ} \mathrm{C}$ and (d) $620^{\circ} \mathrm{C}$. 


\begin{tabular}{|c|c|c|c|c|c|}
\hline Temperature & $\mathrm{Mg} / \mathrm{wt} \%$ & $\mathrm{Ni} / \mathrm{wt}^{\circ} \%$ & $\mathrm{Si} / \mathrm{wt}^{\circ} \%$ & $\mathrm{Fe} / \mathrm{wt} \%$ & $\mathrm{Al} / \mathrm{wt} \%$ \\
\hline $570^{\circ} \mathrm{C}$ & 2.53 & 4.65 & 0.72 & 0.35 & 91.75 \\
\hline $590^{\circ} \mathrm{C}$ & 1.73 & 1.69 & 0.52 & 0.28 & 95.78 \\
\hline $600^{\circ} \mathrm{C}$ & 1.52 & 0.35 & 0.41 & 0.21 & 97.51 \\
\hline $620^{\circ} \mathrm{C}$ & 0.94 & 0.19 & 0.21 & 0.19 & 98.47 \\
\hline
\end{tabular}

Table 2. Wavelength dispersive spectroscopic analyses of joints made at $600^{\circ} \mathrm{C}$ for 10 minutes composition as a function of bonding temperature (wt \%).

\subsection{Effect interlayer thickness on joint properties}

The effects of interlayer thickness on microstructural development across the joint region and subsequent effect on joint micro-hardness and shear strength were investigated. According to Bosco and Zok [8], there exists a critical interlayer thickness at which pore-free bonds are produced. This critical interlayer thickness should correspond to maximum joint strength. Therefore the objective in this section is to identify the critical interlayer thickness that maximizes joint strength. Joints made without the use of an interlayer resulted in the formation of a "planar interface" due to the presence of a layer of surface oxide, which prevents metal to metal contact (see Figure 7a). This was corroborated by studies on the solid-state diffusion bonding of Al-MMC [15]. The inability to achieve effective bonding in the solid-state highlights the need for low melting interlayers. When a $1 \mu \mathrm{m}$ thick $\mathrm{Ni}-\mathrm{Al}_{2} \mathrm{O}_{3}$ coating was used as the interlayer a thin joint zone was achieved (see Figure 7b). However a WDS analysis of this region indicated the presence of a higher concentration of $\mathrm{Al}_{2} \mathrm{O}_{3}$ when compared to bonds made using a pure nickel coating of the same thickness. This was attributed to the presence of nano-sized $\mathrm{Al}_{2} \mathrm{O}_{3}$ particles in the joint zone and the presence of residual surface oxide.

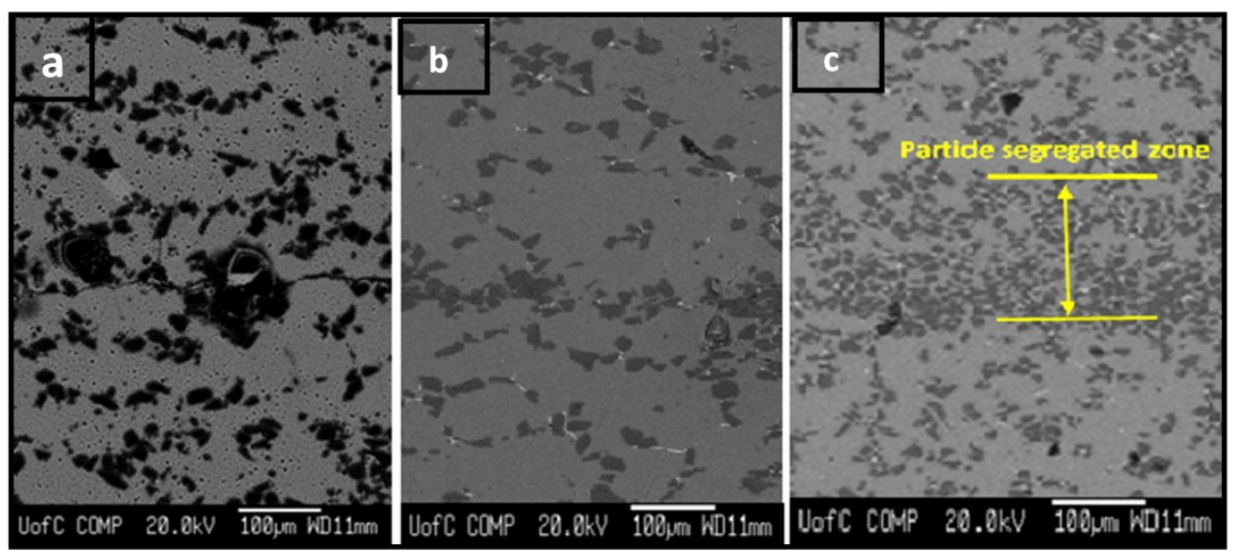

Figure 7. Microstructure of joints bonded at $600^{\circ} \mathrm{C}$ for 10 min using (a) no-interlayer used (b) $1 \mu \mathrm{m}$ thick $\mathrm{Ni}-\mathrm{Al}_{2} \mathrm{O}_{3}$ coating (c) $9 \mu \mathrm{m}$ thick $\mathrm{Ni}-\mathrm{Al}_{2} \mathrm{O}_{3}$ coating [32].

Figures 8 show that the width of the segregated zone increased with increasing coating thickness. At a coating thickness of $2 \mu \mathrm{m}$ a more chemically homogeneous joint was created 
however WDS analysis showed pockets of oxide with the following composition $65.56 \mathrm{wt} \%$ and $28.15 \mathrm{wt} \%$ were still present at the interface. When the coating thickness was increased to $4 \mu \mathrm{m}$, a $95 \mu \mathrm{m}$ wide segregated zone was at the joint center and the concentration of nickel remaining at the interface after bonding increased from $0.47 \mathrm{wt} \%$ with $3 \mu \mathrm{m}$ thick coating to $0.58 \mathrm{wt} \%$ when a $4 \mu \mathrm{m}$ thick coating (see Table 3). Further increase in coating thickness to $5 \mu \mathrm{m}$, resulted in the formation of a $110 \mu \mathrm{m}$ wide segregated zone while the nickel increased to $0.97 \mathrm{wt} \%$.

\begin{tabular}{|c|c|c|c|c|c|}
\hline $\begin{array}{c}\text { Interlayer } \\
\text { thickness }(\mu \mathrm{m})\end{array}$ & $\mathrm{Mg} / \mathrm{wt} \%$ & $\mathrm{Ni} / \mathrm{wt} \%$ & $\mathrm{Si} / \mathrm{wt} \%$ & $\mathrm{Fe} / \mathrm{wt} \%$ & $\mathrm{Al} / \mathrm{wt} \%$ \\
\hline 1 & 0.46 & 0.37 & 0.53 & 0.22 & 98.42 \\
\hline 2 & 0.83 & 0.49 & 0.62 & 0.19 & 97.87 \\
\hline 3 & 0.98 & 0.47 & 0.67 & 0.21 & 97.67 \\
\hline 4 & 0.97 & 0.58 & 0.72 & 0.27 & 97.46 \\
\hline 5 & 0.84 & 0.97 & 0.53 & 0.18 & 97.48 \\
\hline 7 & 0.86 & 0.88 & 0.71 & 0.38 & 97.17 \\
\hline 9 & 1.05 & 1.01 & 0.69 & 0.24 & 97.01 \\
\hline 11 & 1.13 & 1.45 & 0.65 & 0.52 & 96.25 \\
\hline 13 & 0.99 & 1.63 & 0.67 & 0.97 & 95.74 \\
\hline
\end{tabular}

Table 3. WDS analysis of joints made at $600^{\circ} \mathrm{C}$ for 10 minutes as a function of interlayer thickness

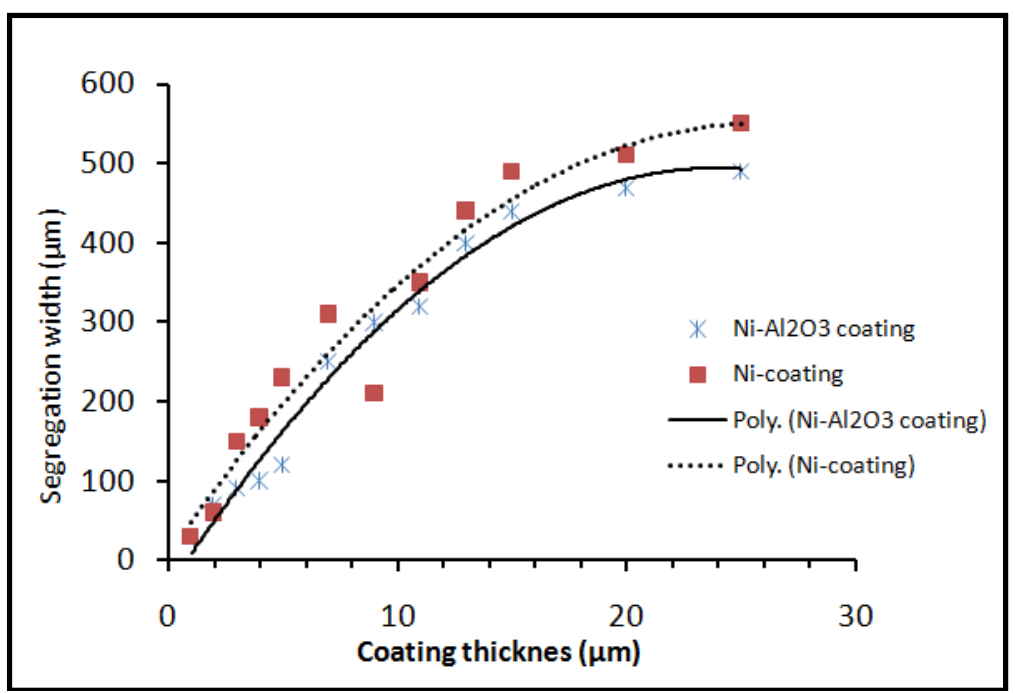

Figure 8. Width of the particle segregated zone formed at within the joint as a function of interlayer thickness for pure $\mathrm{Ni}$ coating and $\mathrm{Ni}-\mathrm{Al}_{2} \mathrm{O}_{3}$ coating $\left[{ }^{32}\right]$. 
The increase in the width of the segregated zone was attributed to increased liquid formation with increasing coating thickness. As the width of the eutectic liquid increases more $\mathrm{Al}_{2} \mathrm{O}_{3}$ particles are immersed in the liquid phase. These particles are pushed by the solid/liquid interface during isothermal solidification [5].

The width of the particle segregated zone was significantly lower than that achieved when pure Ni-coatings are used as the interlayer. The difference in the width of the segregated zone between joint bonded using pure $\mathrm{Ni}$ coating and $\mathrm{Ni}-\mathrm{Al}_{2} \mathrm{O}_{3}$ coating was attributed to the presence of nano-size $\mathrm{Al}_{2} \mathrm{O}_{3}$ particle in the joint center and a reduction in the concentration of $\mathrm{Ni}(81.6 \mathrm{wt} \%)$ present in the coating, when $\mathrm{Ni}-\mathrm{Al}_{2} \mathrm{O}_{3}$ is used (see Figure $13 \mathrm{~b}$ ).

\subsection{Effect of nano-sized particle on joint properties}

The effect of nano-sized particles on the microstructural development across the joint region was studied using energy dispersive spectroscopy (EDS). Figure 9(a) shows the microstructure of a joint bonded using a $5 \mu \mathrm{m}$ thick $\mathrm{Ni}$ coating dispersed with $50 \mathrm{~nm} \mathrm{Al}_{2} \mathrm{O}_{3}$ particles. From the micrograph a $50 \mu \mathrm{m}$ wide particle segregated zone was seen within the joint center. Also present at the center of the joint are dark clumps, which EDS analysis suggested are oxide particles (Figure $10 \mathrm{a}$ and $\mathrm{b}$ ). The presence of the oxide clusters observed, are likely $\mathrm{Al}_{2} \mathrm{O}_{3}$ particles which agglomerated during the deposition process. When the coating particle size was increased to $500 \mathrm{~nm} \mathrm{Al}_{2} \mathrm{O}_{3}$, a similar result was obtained (see Figure.9b). WDS analyses of the joints as a function of particle size indicated that the $\mathrm{Ni}$ concentration of $0.95 \mathrm{wt} \%$ and $0.79 \mathrm{wt} \%$ for samples bonded using $500 \mathrm{~nm}$ and $50 \mathrm{~nm}$ respectively. The lower concentration obtained when $50 \mathrm{~nm}$ particles are used suggest a faster diffusivity of $\mathrm{Ni}$ during the bonding process. This was attributed to greater surface contact between the uncoated $\mathrm{Al}-6061$ sample and the $\mathrm{Ni}_{-} \mathrm{Al}_{2} \mathrm{O}_{3}$ coating surface. Analysis of the roughness using SEM indicated that the surface roughness increased from $0.1 \mu \mathrm{m}$ for coatings containing $50 \mathrm{~nm}$ particles to $0.25 \mu \mathrm{m}$ for coating containing $500 \mathrm{~nm}$ particles.

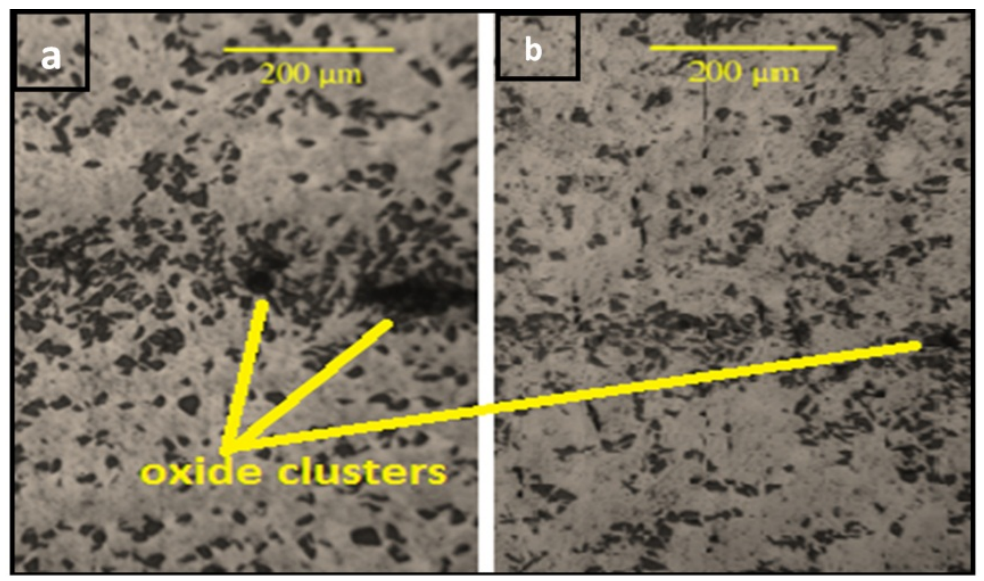

Figure 9. Microstructure of joints bonded at $600^{\circ} \mathrm{C}$ for 10 min using (a) $5 \mu \mathrm{m}$ thick $\mathrm{Ni}-(50 \mathrm{~nm}) \mathrm{Al}_{2} \mathrm{O}_{3}$ (b) $5 \mu \mathrm{m}$ thick Ni-(500nm) $\mathrm{Al}_{2} \mathrm{O}_{3}$ [32]. 


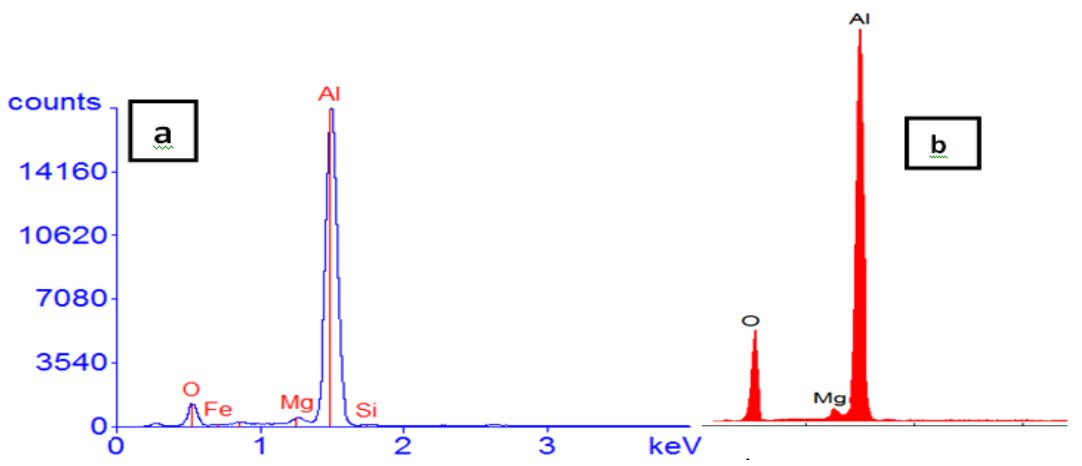

Figure 10. EDS analyses of joints bonded at $600^{\circ} \mathrm{C}$ for 10 min using (a) $5 \mu \mathrm{m}$ thick $\mathrm{Ni}-(500 \mathrm{~nm}) \mathrm{Al}_{2} \mathrm{O}_{3}$ (b) $5 \mu \mathrm{m}$ thick $\mathrm{Ni}-(50 \mathrm{~nm}) \mathrm{Al}_{2} \mathrm{O}_{3}[33]$

The micrograph shown in Figure 9 a thin segregated zone was formed at the joint center in both cases. The hypothesis is that the difference in the width of the segregated zone obtained is dependent on the differences in particle size, surface roughness of the coating and the distribution of the nano-sized particles in the joint zone during bonding. The presence of nano- $\mathrm{Al}_{2} \mathrm{O}_{3}$ along the interface was confirmed by TEM analyses which indicated that the nano-particles are arranged along the grain boundary as shown in Figure 11 which would impart a pinning effect as described by Orowan [24].

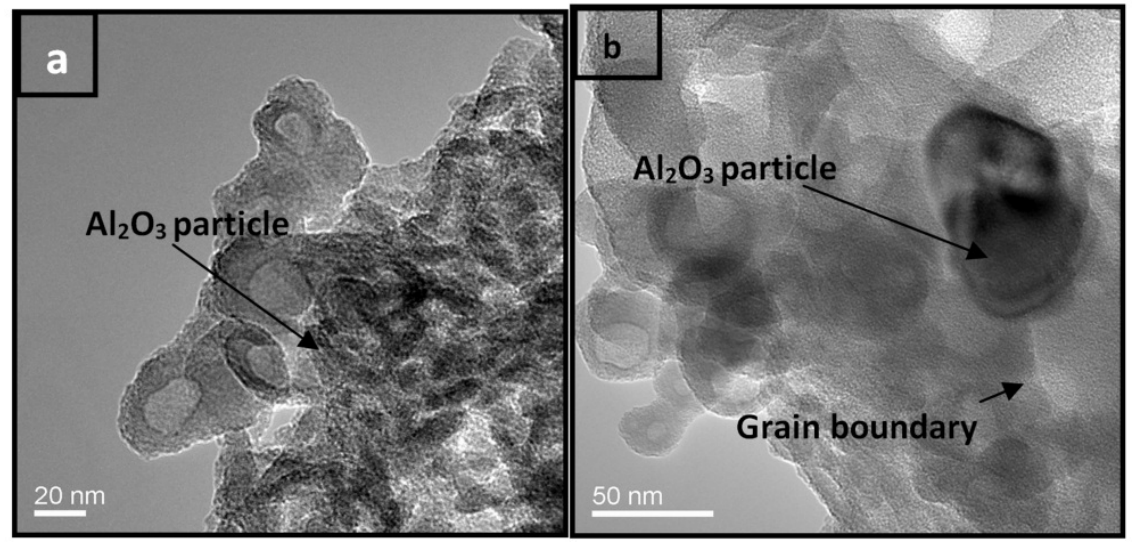

Figure 11. (a) TEM image of the bonded joint when nano-sized $\mathrm{Al}_{2} \mathrm{O}_{3}$ particles are used in the interlayer and (b) TEM image of a nano- $\mathrm{Al}_{2} \mathrm{O}_{3}$ particle located at a grain boundary [33].

\section{Effect of bonding variable on the mechanical properties of the joint}

\subsection{Effect of bonding time the joint shear strength}

The shear strength of joints made as a function of bonding time is shown in Figure 12 (a). The graph show that the shear strength increased with increasing bonding time from 68 


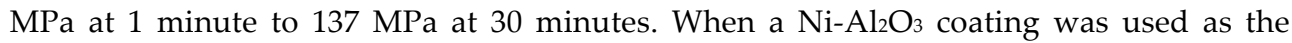
interlayer for a bonding time of 10 minutes, shear strength of $136 \mathrm{MPa}$ was recorded. However when a pure $\mathrm{Ni}$ coating was used under that same bonding conditions, shear strength of $117 \mathrm{MPa}$ was achieved [23]. The differences in joint shear strengths obtained were attributed to the presence of a nano-sized dispersion of $\mathrm{Al}_{2} \mathrm{O}_{3}$ particles within the joint and the precipitation of nickel aluminide phases within the joint region. Shen et al. [34] showed that the increase in yield strength of the nano-particle reinforced aluminum alloy is related to particulate-dislocation interaction by means of the Orowan bowing mechanism. Orowan theory suggests nano-sized particles act as barriers to dislocation motion. This mechanism leads to dislocation pile-up and an increase in the joint shear strength $\left[{ }^{35}\right]$.

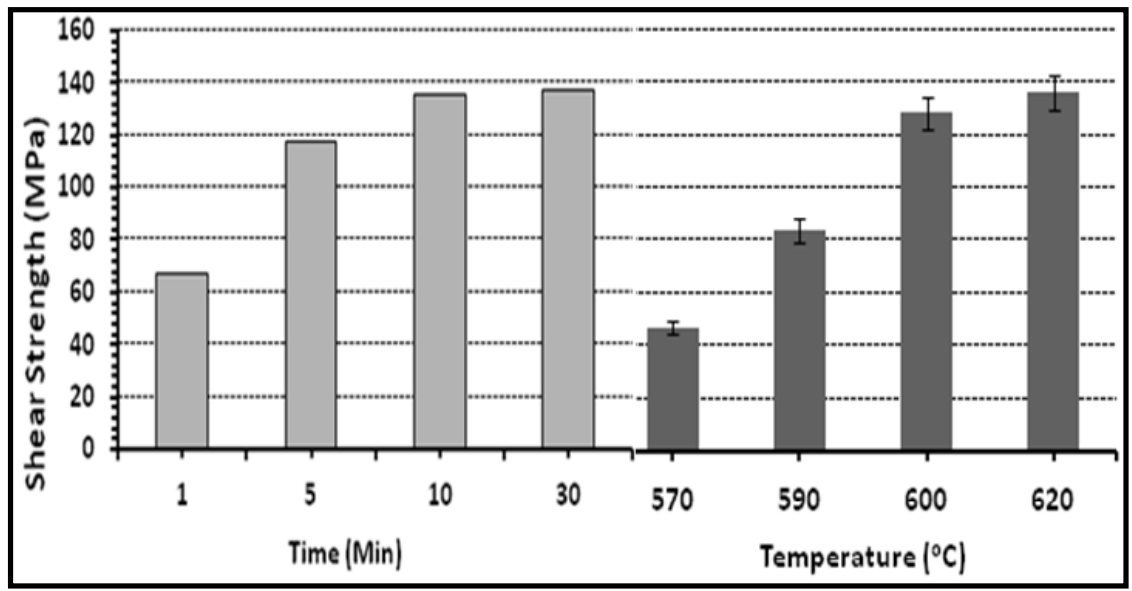

Figure 12. (a) Effect of bonding time on joint strength using $5 \mu \mathrm{m}$ thick $\mathrm{Ni}-\mathrm{Al}_{2} \mathrm{O}_{3}$ coating at a bonding temperature of $600^{\circ} \mathrm{C}$ and (b) Effect of bonding temperature on joint shear strengths made using $5 \mu \mathrm{m}$ thick $\mathrm{Ni}-\mathrm{Al}_{2} \mathrm{O}_{3}$ coatings for 10 minutes $[23,24]$.

The fractured surfaces of the shear tested joints were analyzed to identify the mechanism of joint failure. Figure 13(a) shows the fractured surface of a bond made for a bonding time of 1 minute. The fractograph shows an undulating surface containing shear plastic deformation with some cleavage facets indicating a mixed failure mode. The fracture appeared to have propagated through the bond-line. The result of the fractographic analyses suggests that the mechanism of failure transitioned from brittle to ductile as the bonding time increases. When the bonding time was increased to 10 minutes (see Figure 18b). The surface was characterized by an undulating appearance of plastic deformation indicative of ductile mode of failure. Additionally, fractured micro- $\mathrm{Al}_{2} \mathrm{O}_{3}$ particles were observed at the fractured surface, indicating a transgranular fracture through the bond-line. 
XRD analyses of the fractured surfaces of bonds made at 1 and 10 minutes are shown in Figure 14. The results indicated the presence of peaks for phases such as $\mathrm{AlFe}_{6} \mathrm{Si}\left(2 \theta=38^{\circ}\right)$, $\mathrm{Al} 9 \mathrm{FeNi}$ and AlFeSi. The literature showed that these ternary compounds forms readily in $\mathrm{Al}-\mathrm{Mg}$-Si-Fe-Ni systems through various peritectic reactions [17]. In addition, binary crystal phases such as $\mathrm{Al}_{3} \mathrm{Ni}, \mathrm{Ni} 3 \mathrm{Si}\left(2 \theta=78^{\circ}\right)$. $\mathrm{Al}_{3} \mathrm{Si}$ and $\mathrm{Al}_{2} \mathrm{O}_{3}$ compounds were also identified.

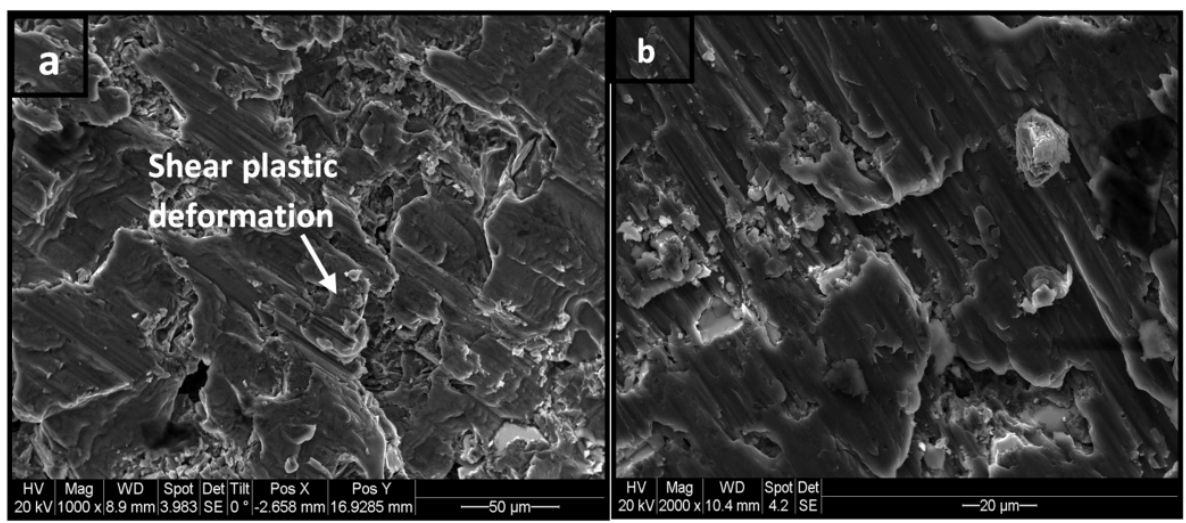

Figure 13. SEM micrograph the fractured surface of a bond made at $600^{\circ} \mathrm{C}$ with $5 \mu \mathrm{m}$ thick $\mathrm{Ni}-\mathrm{Al}_{2} \mathrm{O}_{3}$ for: (a) 1 minute and (b) 10 minutes

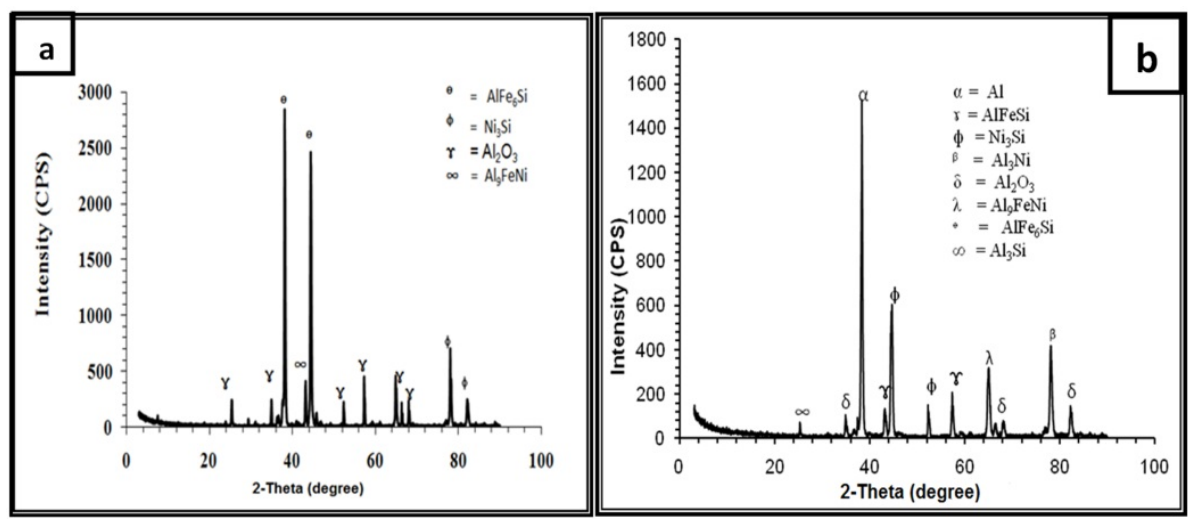

Figure 14. XRD analysis of the fractured surface of a bond made with $5 \mu \mathrm{m}$ thick $\mathrm{Ni}-\mathrm{Al}_{2} \mathrm{O}_{3}$ for (a) 1 minute and (b) 10 minutes ind

\subsection{Effect of temperature on joint shear strength}

Joint shear strengths measured as a function of bonding temperature were obtained using a single lap shear test. A comparison of the joint shear strengths of bonds made at 570, 590, 
600 and $620^{\circ} \mathrm{C}$ is shown in Figure $12(\mathrm{~b})$. The test result show that the shear strength increased with increasing bonding temperature from $45 \mathrm{MPa}$ at $570^{\circ} \mathrm{C}$ to $138 \mathrm{MPa} 600^{\circ} \mathrm{C}$. This increase in joint strength was attributed to the presence of nano-sized ceramic particles and the precipitation of intermetallic phases within the joint region. The formation of these nickel aluminide phases increased with increasing bonding temperature. Specimens bonded at $620^{\circ} \mathrm{C}$ gave the highest bond strength of $136 \mathrm{MPa}$. The effect of the nano-particles and the precipitated intermetallics on the composite was discussed by Zhang and Chan [45] and results in Orowan strengthening as discussed in the previous sections.

In order to compare the effect of bonding temperature on joint failure mechanisms the fractured surfaces were examined using SEM. The results collected suggested that the ductility of the joint increased with increasing bonding temperature. For a bonding temperature of $570^{\circ} \mathrm{C}$ a mix failure mode was observed with both shear rupture dimples and cleavage planes (Figure 15a). An XRD analysis of the fractured surface indicated a high concentration of $\mathrm{Al}_{2} \mathrm{O}_{3}$ particles (see Figure 16a). This indicated that at this temperature the matrix-particle (M-P) interface was the weakest point for crack propagation giving the lowest joint strength of $(53 \mathrm{MPa})$. Fracture propagation was observed through the bond-line. When the bonding temperature was increased to between $590^{\circ} \mathrm{C}$ and $620^{\circ} \mathrm{C} \mathrm{XRD}$ analyses of the fracture indicated that the amount of intermetallic formed within the joint increased to include the binary compounds $\mathrm{Al}_{3} \mathrm{Si}, \mathrm{Al}_{3} \mathrm{Ni}$ and $\mathrm{Ni}_{3} \mathrm{Si}$ which suggested that failure propagated through the bond-line. Additionally, peaks of the ternary phases AlFeSi $(2 \theta=37$ and $\left.68^{\circ}\right)$ and $\mathrm{Al} 9 \mathrm{FeSi}\left(2 \theta=78\right.$ and $\left.84^{\circ}\right)$. The presence of these compounds confirms the formation of peritectic reactions during bonding. At $620^{\circ} \mathrm{C}$ the fractured surface was characterized by shear ruptured dimples indicating a ductile failure mode which occurred in the parent metal adjacent to the bond-line.

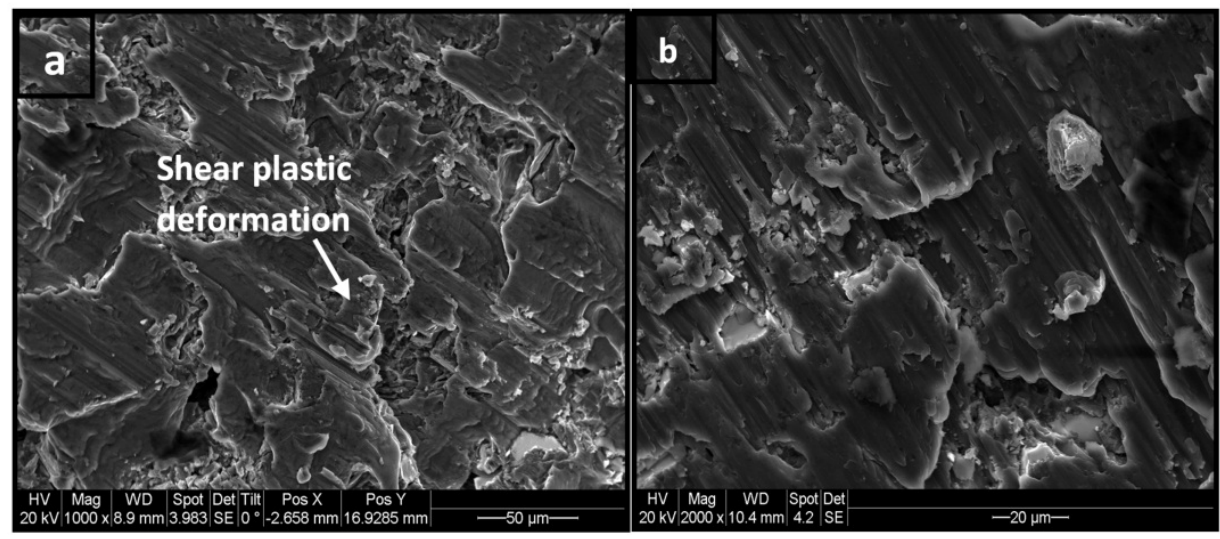

Figure 15. (a) SEM micrograph of the fractured surface of a joint made using a $5 \mu \mathrm{m}$ thick $\mathrm{Ni}-\mathrm{Al}_{2} \mathrm{O}_{3}$ coatings at $570^{\circ} \mathrm{C}$ and (b) $620^{\circ} \mathrm{C}$. 

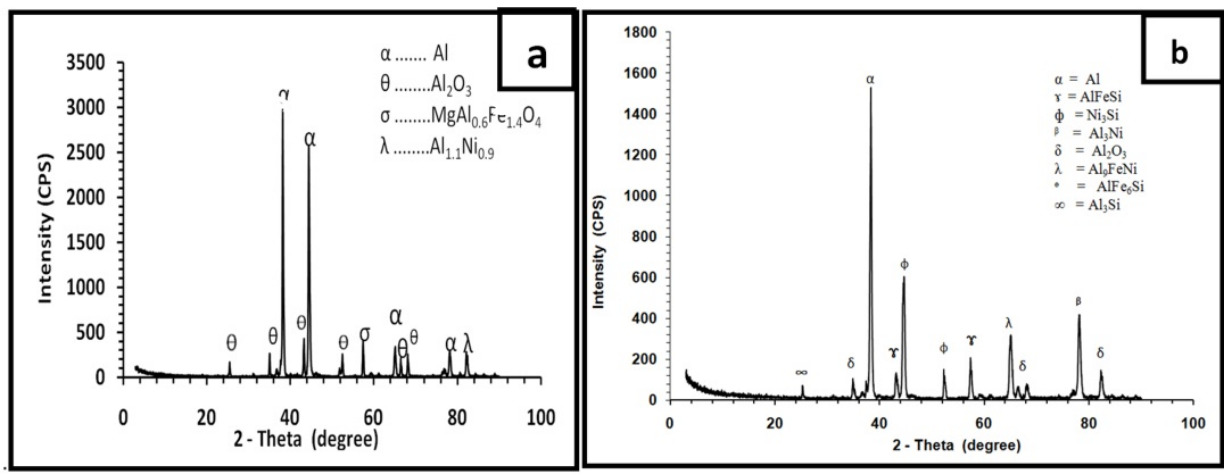

Figure 16. XRD spectrum of the fractured surface of a joint made using a $5 \mu \mathrm{m}$ thick $\mathrm{Ni}-\mathrm{Al}_{2} \mathrm{O}_{3}$ coatings at (a) $570^{\circ} \mathrm{C}$ and (b) $620^{\circ} \mathrm{C}$.

\subsection{Effect of coating thickness on shear strength measurements}

Figure 17 (a) shows the variation in joint shear strength values as a function of coating thickness. The graph shows that the shear strength increased with increasing coating thickness from $53 \mathrm{MPa}$ at $1 \mu \mathrm{m}$ to $144 \mathrm{MPa}$ at $11 \mu \mathrm{m}$. This increase in joint strength was attributed to three phenomena: the presence of nano-size $\mathrm{Al}_{2} \mathrm{O}_{3}$ particles in the joint center, the segregation of micro $\mathrm{Al}_{2} \mathrm{O}_{3}$ particle to the joint zone and the precipitation of intermetallic phases such as $\mathrm{Al}_{3} \mathrm{Si}, \mathrm{Ni}_{3} \mathrm{Si}, \mathrm{Al}_{3} \mathrm{Ni}$, and $\mathrm{Al}{ }_{9} \mathrm{FeNi}$ within the joint region. As discussed in the previous sections, for composites containing nano-sized particles, strengthening is often explained by the Orowan mechanism [36,37]. Orowan bypassing theory shows that when smaller particle reinforcements are used the result is a more effective pinning of dislocation motion compared to when micro-particles are used. This mechanism leads to an increase in joint strength and hardness.



Figure 17. (a) Joint shear strengths as a function of particle size using $5 \mu \mathrm{m}$ thick coatings (b) Shear strength profile plotted as a function of $\mathrm{Ni}-\mathrm{Al}_{2} \mathrm{O}_{3}$ coating thickness. 
When the coating thickness was increased beyond $11 \mu \mathrm{m}$, a decline in the strength of the joints was observed. At a coating thickness of $13 \mu \mathrm{m}$, a joint strength of $80 \mathrm{MPa}$ was recorded. This reduction in joint strength was attributed to the formation of densely packed micro- $\mathrm{Al}_{2} \mathrm{O}_{3}$ particle-rich regions along the bond interface and also due to an increase in the volume of intermetallics compounds such as $\mathrm{AlFe}_{3} \mathrm{Si}$ within the joint. The literature shows that the volume fraction of the micro- $\mathrm{Al}_{2} \mathrm{O}_{3}$ particles within the joint is inversely proportional to the joint ductility. Therefore, as the width of the particle segregated zone increased the ductility of the joint decreases. This leads to embrittlement of the joint region and causes a reduction in joint strength [38,39, 40, 41]. The findings published in the scientific literature supports the results collected in this study.

Fractured surfaces of the shear tested joints were analyzed to identify the mechanism of joint failure and the composition of the fractured surfaces. Figures 18 shows the micrographs of the typical fractured surfaces obtained for joints that were bonded using coating thickness ranging from 1 to $3 \mu \mathrm{m}$, respectively. Fractographic analyses revealed that the fractured surface contained cleavage planes, which propagated through the bond-line. In addition, $\mathrm{Al}_{2} \mathrm{O}_{3}$ particles were visible at the fractured surface. Examination of the fractured surfaces revealed characteristics of a brittle fracture which suggest that insufficient eutectic liquid is formed when using coating thickness between 1 and $3 \mu \mathrm{m}$. Composition analysis of the fractured surfaces using XRD indicated the presence of peaks for $\mathrm{Al}_{2} \mathrm{O}_{3}, \mathrm{Ni}_{3} \mathrm{Si}$ and $\mathrm{Ni}_{17} \mathrm{Al}_{3.9} \mathrm{Si}_{5.1} \mathrm{O}_{48}$ compounds.

When an interlayer thickness of $11 \mu \mathrm{m}$ (see Figure 19a) was used, the fractured surface showed evidence of both shear plastic deformation and fractured micro- $\mathrm{Al}_{2} \mathrm{O}_{3}$ particles indicating a ductile transgranular fracture. Samples bonded at this condition had the highest shear strength. This indicated a critical combination of segregated micro- $\mathrm{Al}_{2} \mathrm{O}_{3}$ particles and nano- $\mathrm{Al}_{2} \mathrm{O}_{3}$. Crack propagation occurred in the base metal adjacent to the bond-line. The results suggest that within coating thickness range of 5 to $11 \mu \mathrm{m}$, sufficient eutectic liquid is produced, which facilitate good particle to matrix bonding resulting increased joint strength. The XRD spectrum shown in Figure 19 (b) indicated the presence of $\mathrm{Ni}_{3} \mathrm{Si}$, $\mathrm{MgAl}_{2} \mathrm{O}_{4}$ and $\mathrm{Al}_{2} \mathrm{O}_{3}$ compound at the fractured surface. Increasing the coating thickness beyond $11 \mu \mathrm{m}$ resulted in the gradual transition of the fracture mode from ductile to brittle. At a coating thickness of $13 \mu \mathrm{m}$ thick $\mathrm{Ni}_{-} \mathrm{Al}_{2} \mathrm{O}_{3}$ coating (see Figure 20), the surface is characterized by dimples along the interparticle regions indicating a ductile failure through the particle-rich regions along the bond-line. XRD analyses of the fractured surfaces indicate the presence of peaks for $\mathrm{Al}_{2} \mathrm{O}_{3}, \mathrm{NiAl}_{2} \mathrm{O}_{4}$ and $\mathrm{AlFe} 3 \mathrm{Si}$ compound at the fractured surface (see Figure 20b).

The results suggest that the ductility of the joint region increased with increasing coating thickness up to $9 \mu \mathrm{m}$. When the coating thickness was increased beyond $9 \mu \mathrm{m}$ the joint region transitioned from ductile to brittle. These transitions were attributed to an increase in the volume of eutectic liquid that forms with increasing coating thickness leading to interparticle contact. 




Figure 18. (a) SEM micrograph (b) cross-section (Mag. X10) and (c) XRD analysis of the fractured surface for a bond made with a $3 \mu \mathrm{m}$ thick $\mathrm{Ni}-\mathrm{Al}_{2} \mathrm{O}_{3}$ coating for 10 minutes at $600^{\circ} \mathrm{C}$.
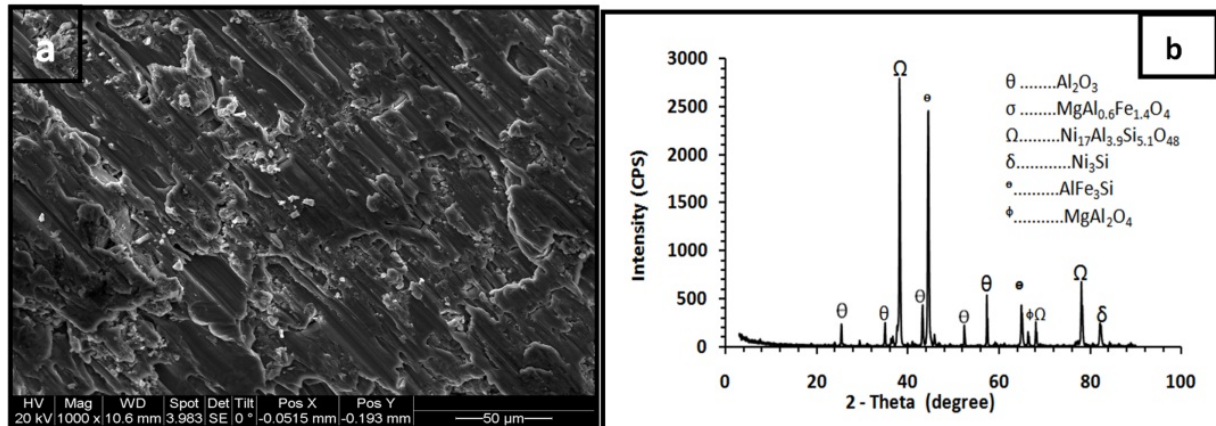

Figure 19. (a) SEM micrograph (b) cross-section (Mag. X10) and (c) XRD analysis of the fractured surface for a bond made with an $11 \mu \mathrm{m}$ thick $\mathrm{Ni}-\mathrm{Al}_{2} \mathrm{O}_{3}$ coating for 10 minutes at $600^{\circ} \mathrm{C}$.


Figure 20. (a) SEM micrograph and (b) XRD analysis of the fractured surface for a bond made with a 13 $\mu \mathrm{m}$ thick $\mathrm{Ni}-\mathrm{Al}_{2} \mathrm{O}_{3}$ coating for 10 minutes at $600{ }^{\circ} \mathrm{C}$.

\subsection{Effect of interlayer particle size shear strength measurements}

Figure 17(b) show the joint shear strength graph as a function of interlayer particle size. The result indicated that joint shear strength increased with decreasing particle size from 138 
$\mathrm{MPa}$ with $500 \mathrm{~nm}$ to142 MPa with $50 \mathrm{~nm}$. This increase in joint shear strength was attributed to better distribution of nano-sized particles within the interlayer when smaller particle sizes are used. In both cases higher shear strengths were obtained than when pure Ni coating is used $(117 \mathrm{MPa})$ [23]. The results indicate that joint strength of up to $90 \%$ that of the base metal (BM) is achievable when using a $50 \mathrm{~nm}$ diameter nano-sized particle-reinforced interlayer. Tjong [42] showed that the nano-particle size has a strong effect on the yield strength. The author suggested that a particle size of $100 \mathrm{~nm}$ is a critical value for improving the yield strength of nano-composites. Below this critical value the yield strength increases significantly with decreasing particle size. Similar results were obtained by Gupta and coworkers [43, 44]. Zhang and Chen [45] showed that the Orowan stress plays a major role in strengthening the nano-composites.

Figure 21 shows the fractured surface for a bond made using a $5 \mu \mathrm{m} \mathrm{Ni}-50 \mathrm{~nm} \mathrm{Al}_{2} \mathrm{O}_{3}$ particle. The fractograph showed shear plastic deformation, indicative of ductile fracture with a crack propagating primarily through the bond-line and a section of the base metal adjacent to the bond-line. A similar result was obtained when a dispersed particle size of 50 $\mathrm{nm}$ were used in the coating. XRD analyses of the fractured surfaces indicated the presence of peaks for $\mathrm{Al}_{2} \mathrm{O}_{3}, \mathrm{NiAl}_{2} \mathrm{O}_{4}$ and $\mathrm{Al}_{11} \mathrm{Ni}$ compound at the fractured surface.

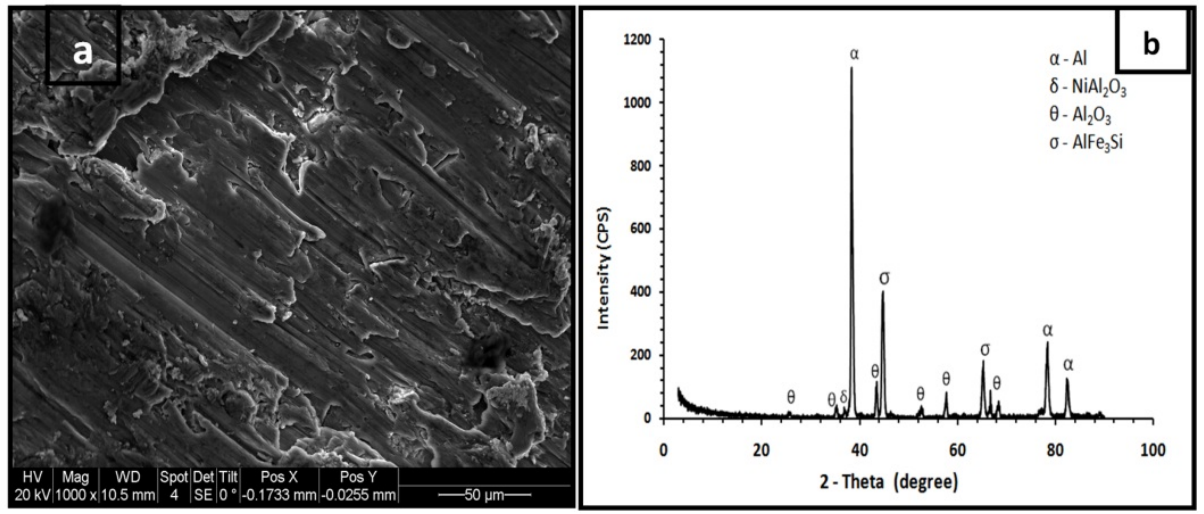

Figure 21. (a) SEM micrograph and (c) XRD analysis of the fractured surface for a bond made with 5 $\mu \mathrm{m}$ thick $\mathrm{Ni}-(50 \mathrm{~nm}) \mathrm{Al}_{2} \mathrm{O}_{3}$ for 10 minutes at $600^{\circ} \mathrm{C}$.

\section{Mechanism of joint formation}

The mechanism of bond formation using composite $\mathrm{Ni}_{-} \mathrm{Al}_{2} \mathrm{O}_{3}$ coating is discussed in this section. The experimental results and the scientific literature show that the joint formation during transient liquid phase diffusion bonding is completed in five distinct stages: interfacial contact and solid-state diffusion, eutectic melting and base metal dissolution, and isothermal solidification. These stages will be discussed thoroughly with reference to the change in composition across the joint region. Mathematical models for predicting the parameter settings when nano-composite coatings are used in joining will also be presented. The sub-section of this topic are as follows: 


\subsection{Interfacial contact and Solid-state diffusion}

The first stage of transient liquid phase bonding involved heating the sample to the bonding temperature. During this stage of bonding, two mechanisms are thought to occur simultaneously, firstly an increase in interfacial contact between the coating surface and the $\mathrm{Al} 6061$ surface and secondly, solid-state diffusion along the coating/MMC contact interface. The initial contact area between the one side of the coating and the metal surfaces is only a small fraction of the theoretical area available, due to the presences of micro-asperities of the surface of both the metal sample and the coating. However, under the effects of heating and an external pressure an intimate contact can be establish at the bonding surfaces, as the micro-asperities suffer plastic deformation. As the temperature increases greater plastic flow is achieved at the interface and the percentage contact area increases. This increase in the contact area results in an increased diffusivity of the solute (Ni) into the base metal. During the heating stage Ni diffuses deep into the Al-MMCs resulting in the formation of complex intermetallic compounds.

Figure 22(a) shows an SEM micrograph of a joint bonded using a $15 \mu$ m thick $\mathrm{Ni}-\mathrm{Al}_{2} \mathrm{O}_{3}$ coating as the interlayer. The joint was made at a bonding temperature of $600^{\circ} \mathrm{C}$ for 1 minute and shows three distinct reaction layers at the interlayer/MMC interface. The nano- $\mathrm{Al}_{2} \mathrm{O}_{3}$ particles that were co-electrodeposited with Ni can are clearly shown in Figure 22.

The composition of the reaction layers was determined quantitatively by energy dispersive spectroscopy (EDS) analysis and is shown in Table 4. The formation of reaction layers (L2 and $\mathrm{L}_{3}$ ) shown in Figure 22, occurred as a result of the inter-diffusion of Ni and Al. EDS analysis showed that $\mathrm{L}_{1}$ was composed of a Ni-Al layer dispersed with nano-sized $\mathrm{Al}_{2} \mathrm{O}_{3}$ particles after a bonding time of 1 minute (see Table 4). Reaction layer L2 on the other hand appears to be a nickel-aluminide with compositions of 50.7 (at \%) Ni and 46.70(at \%) Al. The L3 layer contains approximately 24.30 (at \%) Ni and 77.0 (at \%) Al, which is likely to be $\mathrm{NiAl}_{3}$ intermetallic. This compound is believed to form due to the low solubility of $\mathrm{Ni}$ in Al. This has been reported to be approximately 2.9 at $\%$ [46]. The saturation of the aluminum interface through the inter-diffusion of $\mathrm{Ni}$ and $\mathrm{Al}$ leads to the precipitation of the nickel aluminide intermetallic $\mathrm{NiAl}_{3}$.

The phase diagram of the $\mathrm{Ni}+\mathrm{Al}$ system indicates the thermodynamic stability of the $\gamma^{\prime}-$ $\mathrm{Ni}_{3} \mathrm{Al}$ phase when formed in the nickel concentration range of about (74 to 76) at.\% [46]. Additionally, the phase diagram of the $(\mathrm{Ni}+\mathrm{Al})$ system proposed by Nash et al. [47] showed that for aluminum concentrations exceeding $40 \mathrm{~mol} \%$, there exist three coexistence fields: $\left(\mathrm{Al}+\mathrm{NiAl}_{3}\right),\left(\mathrm{NiAl}_{3}+\mathrm{Ni}_{2} \mathrm{Al}_{3}\right)$ and the non-stoichiometric intermetallic $\beta-\mathrm{NiAl}$, which is formed in the concentration range $43 \mathrm{~mol} \%$ to $59 \mathrm{~mol} \%$ aluminum. Rog et al. [48] determined the Gibbs free energy of formation for various intermetallic compounds forming in the $\mathrm{Ni}+\mathrm{Al}$ system. The results showed that within the temperature range of $570^{\circ} \mathrm{C}$ to $620^{\circ} \mathrm{C}$ (843K to $\left.893 \mathrm{~K}\right)$ the nickel aluminide compounds listed in Table 4 are formed.

Based on the scientific literature, the compound formed in the reaction layer $\mathrm{L}_{3}$ is likely to be the $\mathrm{NiAl}_{3}$. This compound also appears on the right side of Equation 9 and is believed to 
form due to low solubility of $\mathrm{Ni}$ in $\mathrm{Al}$ which has been reported to be approximately 2.9 at $\%$ [46]. The saturation of the aluminum interface through the diffusion of Ni can lead to the precipitation of the nickel aluminide intermetallic $\mathrm{NiAl}_{3}$. The composition of $\mathrm{L}_{2}$ indicates that the compound is likely $\mathrm{NiAl}$.

\begin{tabular}{cc}
\hline Phase & $\Delta \mathrm{G}_{\mathrm{f}}^{\mathrm{o}}\left(\mathrm{kJ} \cdot \mathrm{mol}^{-1}\right)$ \\
\hline $\mathrm{Ni}+\mathrm{Al}=\mathrm{NiAl}$ & $-133.0+/-1.0$ \\
$\mathrm{Ni}+\mathrm{NiAl}{ }_{3}=\mathrm{Ni}_{2} \mathrm{Al}_{3}$ & $-144.1+/-0.8$ \\
$2 \mathrm{Ni}+3 \mathrm{Al}=\mathrm{Ni}_{2} \mathrm{Al}_{3}$ & $-311.0+/-1.7$ \\
$\mathrm{Ni}+3 \mathrm{Al}=\mathrm{NiAl}_{3}$ & $-166.8+/-0.9$ \\
\hline
\end{tabular}

Table 4. The standard Gibbs free energy values for the chemical reactions with nickel aluminides at $870 \mathrm{~K}[48]$

\begin{tabular}{|c|c|c|c|c|c|}
\hline Layers & $\begin{array}{c}\mathbf{A l} / \\
\mathrm{wt} \%\end{array}$ & $\mathbf{N i} / \mathrm{wt} \%$ & $\mathbf{S i} / \mathbf{w t} \%$ & $\begin{array}{c}\mathbf{M g} / \\
\mathrm{wt} \%\end{array}$ & Compound \\
\hline $\mathrm{L}_{1}$ & 12.5 & 87.5 & 0 & 0 & $\mathrm{Ni}+\mathrm{Al}_{2} \mathrm{O}_{3}$ \\
\hline $\mathrm{L}_{2}$ & 46.71 & 50.67 & 0.27 & 0 & $\mathrm{NiAl}$ \\
\hline $\mathrm{L}_{3}$ & 72.84 & 24.31 & 0 & 0.55 & $\mathrm{NiAl}_{3}$ \\
\hline $\mathrm{L}_{4}$ & 72.84 & 24.31 & 0 & 0.55 & $\mathrm{NiAl} 3$ \\
\hline
\end{tabular}

Table 5. Energy dispersive spectroscopic compositional analyses of the reaction layers developed during bonding ( $\mathrm{wt} \%)$

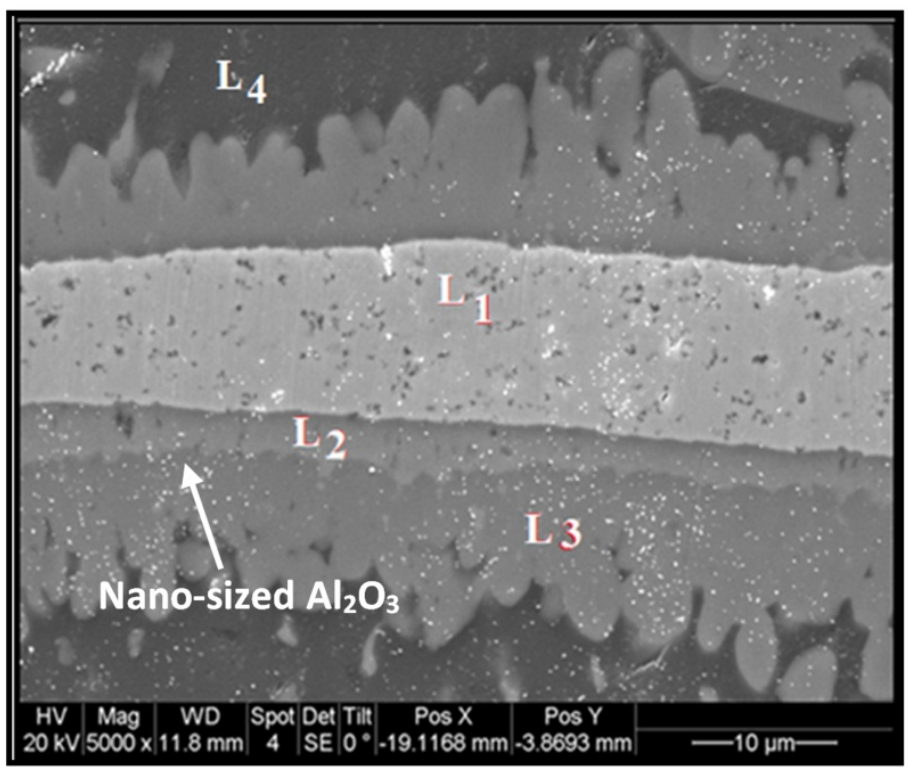

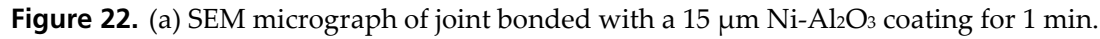




\subsection{Liquid formation and base-metal dissolution}

Immediately following the heating stage, eutectic melting ensues. According to Dmitry et al [50] there are two possible reactions which are capable of producing a liquid at the joint interface within this temperature range $\left(570^{\circ} \mathrm{C}-620^{\circ} \mathrm{C}\right)$. Upon reaching a temperature of $565^{\circ} \mathrm{C}$, the $\mathrm{L}_{2}$ compound reacts with $\mathrm{L}_{4}(88.4 \% \mathrm{Al}$ and $2.08 \% \mathrm{Si})$ to form a eutectic liquid (E1) along the bond interface as predicted by Equation 9 [46]. The compound formed in L2 is consumed in the eutectic reaction and diffuses into the base metal. When the joint region was heated to $577^{\circ} \mathrm{C}$ a second eutectic liquid formed within $\mathrm{L} 4$ as predicted by Equation 10 [49]. The formation of a eutectic liquid layer at the bond interface leads to faster interdiffusion between $\mathrm{Al}$ and the $\mathrm{Ni}$ interlayer and this results in a gradual change in the composition of the joint region.

$$
\begin{gathered}
\mathrm{L}_{1} \stackrel{565^{\circ} \mathrm{C}}{\longrightarrow}(87 \%) \mathrm{Al}+(2 \%) \mathrm{Si}+(11 \%) \mathrm{NiAl}_{3} \\
\mathrm{~L}_{2} \stackrel{577^{\mathrm{O}} \mathrm{C}}{\longrightarrow}(87.5 \%) \mathrm{Al}+(12.5 \%) \mathrm{Si}
\end{gathered}
$$

Dmitry et al. [50] carried out thermodynamic calculations of (Al-Mg-Si-Fe-Ni) quinary systems formed in aluminum alloys. The results showed that in alloys containing Al-Mg-Si-Fe- $\mathrm{Ni}$, numerous ternary and quaternary reactions can occur that has the potential of producing a liquid phase. Some of the phases that contribute to these reactions are shown in Table 6. The XRD analysis of the fractured surfaces shown in the previous also indicated that presence of $\mathrm{AlFe}_{3} \mathrm{Si}$. This phase is possibly a variant of the $\beta$-phase family listed in Table 6.

\begin{tabular}{cccc}
\hline Phase & Designation & Composition $\mathbf{( w t} \%)$ & Density $\left(\mathbf{g} / \mathbf{c m}^{3}\right)$ \\
\hline $\mathbf{A l}{ }_{3} \mathbf{N i}$ & $\varepsilon$ & $42 \mathrm{Ni}$ & 3.95 \\
$\mathbf{M g}{ }_{2} \mathrm{Si}$ & $\mathrm{M}$ & $63.2 \mathrm{Mg} ; 36.8 \mathrm{Si}$ & 4.34 \\
$\mathbf{A}{ }_{9} \mathbf{F e N i}$ & $\mathrm{T}$ & $4.5-14 \mathrm{Fe} ; 18-28 \mathrm{Ni}$ & 3.40 \\
$\mathbf{A} l_{5} \mathrm{FeSi}$ & $\beta$ & $25-30 \mathrm{Fe}, 12-15 \mathrm{Si}$ & 3.45 \\
$\mathbf{A l}_{8} \mathrm{FeMg}$ & $10.9 \mathrm{Fe} ; 14.1 \mathrm{Mg} ; 32.9 \mathrm{Si}$ & 2.82 \\
\hline
\end{tabular}

Table 6. Chemical composition and density of phases formed in Al-Mg-Si-Fe-Ni system [50]

\subsection{Base metal dissolution}

Base metal dissolution is also an important part of the second stage of bonding. Research work published [1,2] on the mechanisms of TLP bonding showed that dissolution of the interlayer and base metal occurs simultaneously at the bonding temperature. In this study, holding at a bonding temperature above $577^{\circ} \mathrm{C}$ resulted in increased diffusion of Ni into the base metal and causes the liquid phase to spread between the bonding surfaces due to the effects of pressure and capillary action. The application of pressure enhances spreading of the liquid phase between the bonding surfaces due to capillary action. This spreading increases the contact area and induces the diffusion of $\mathrm{Ni}$ and $\mathrm{Al}$ into the liquid phase. This 
results in more eutectic liquid formation and an increase in the width of the liquid phase at the joint, due to dissolution of a section of the base metal. Further increase in the bonding time to 5 minutes, resulted in the diffusion of the $\mathrm{Ni}$ into the base metal and away from the joint interface leading to the formation of eutectic or peritectic liquid along the grain boundary as indicated in the EDS analysis of the eutectic microstructure shown in Figure 23.



Figure 23. (a) SEM micrograph of joint bonded using a $25 \mu \mathrm{m}$ Ni foil for $5 \mathrm{~min}$ and (b) EDS analysis of the joint region.

According to published studies [20,1] on the stages of TLP bonding, it is expected that dissolution of the interlayer and base metal occurs simultaneously at the bonding temperature followed by spreading of the liquid phase between the bonding surfaces. This spreading increased the bonded area and enhanced the diffusion of $\mathrm{Ni}$ and $\mathrm{Al}$ into the liquid phase. This continuing diffusion resulted in more liquid formation and an increase in the width of liquid phase. The maximum liquid width attained when using the $\mathrm{Ni}-\mathrm{Al}_{2} \mathrm{O}_{3}$ composite coating as the interlayer was found by Cooke et al [24] to be $W_{\max }=20.6 w_{0}$.

\subsection{Isothermal solidification}

In TLP bonding, prolonged hold time at the bonding temperature for 10 minutes allowed for the diffusion of $\mathrm{Al}$ into the eutectic liquid which caused the composition of the liquid phase to become aluminum rich, resulting in a change in the eutectic composition (see Table 6). The change in the joint composition initiates the isothermal solidification stage of TLP bonding as a function of bonding time since the temperature and interlayer thickness is constant. When the bonding time is increased to 10 minutes the interface is eliminated and the grain size within the joint increased. This disrupts the band of segregated particles at the interface and homogenized the joint zone. When the bonding time was increased to 30 minutes a corresponding increase was seen in grain size, resulting in more uniform distribution of micro- $\mathrm{Al}_{2} \mathrm{O}_{3}$ particles. In the reported studies on transient liquid phase diffusion bonding of Al-MMCs, it was shown that the width of the segregated zone at the joint center increased with increasing bonding time. The opposite of this relationship was seen when using the $\mathrm{Ni}-\mathrm{Al}_{2} \mathrm{O}_{3}$ coating. As the bonding time increased, the width of the 
segregated region decrease. This can be attributed to the heterogeneous nucleation of grains within the joint zone during solidification and this lead to grain refining at the joint. The high resolution SEM micrograph shown in Figure 33 revealed the presence of a nano- $\mathrm{Al}_{2} \mathrm{O}_{3}$ particle at the center of a grain. EDX spectra of the particle showed $\mathrm{Al}$ and $\mathrm{O}$ in high concentrations with traces of $\mathrm{Mg}$. Comparing Gibbs free energy of formation at the bonding temperature for $\mathrm{MgO}(-1195 \mathrm{~kJ} / \mathrm{mol})$ and $\mathrm{Al}_{2} \mathrm{O}_{3}(-985 \mathrm{~kJ} / \mathrm{mol})$ it is found that $\mathrm{Al}_{2} \mathrm{O}_{3}$ is unstable in the presence of $\mathrm{Mg}$ hence it is like that some of the nano-size $\mathrm{Al}_{2} \mathrm{O}_{3}$ will decomposed to form $\mathrm{MgAl}_{2} \mathrm{O}_{4}$ compound.

The segregation of particles during isothermal solidification was accredited to the pushing of strengthening particles by the solidifying liquid-solid interface. Stefanescu [17, 18] showed that particle pushing can be assumed to be a steady-state condition under which the interface velocity can be assumed to be equal the rate of isothermal solidification This rate can be calculated using a model proposed by Sinclair [51]. The constant, $\xi$, signifies the solidification rate of the system. Increasing $\xi$ results in faster solid-liquid interface motion, and a shorter duration of the isothermal solidification stage. The rate of isothermal solidification can be calculated using Equation 11.

$$
\xi=-2(k-1)^{-1} \sqrt{\frac{D}{\pi}} \cdot \frac{\exp \left(\frac{-\xi^{2}}{4 \cdot D}\right)}{\operatorname{erfc}\left(\frac{\xi}{2 \sqrt{D}}\right)}
$$

Where $k$ is a partition coefficient given by $\frac{C_{L \alpha}}{C_{\alpha L}}$ and D is the diffusivity of Ni into Al. The diffusivity at $570^{\circ} \mathrm{C}$ is $4.69 \times 10^{-13} \mathrm{~m}^{2} / \mathrm{s}$, when the bonding temperature is increased to $620^{\circ} \mathrm{C}$, the diffusivity also increased to $1.58 \times 10^{-12} \mathrm{~m}^{2} / \mathrm{s}$. This increase in diffusivity is reflected in a faster solid-liquid interface rate $(\xi)$ and a shorter isothermal solidification stage.

The final concentration of $\mathrm{Ni}\left(C_{\mathrm{L \alpha}}\right)$ was taken from the Al-Ni-Si phase diagram [30] to be 4.9 wt $\%$ for the bonding temperature of $620^{\circ} \mathrm{C}$. The diffusivity of $\mathrm{Ni}$ in $\mathrm{Al}$ at $620^{\circ} \mathrm{C}$ is $\mathrm{D}=1.58 \mathrm{x}$ $10^{-12} \mathrm{~m}^{2} / \mathrm{s}[25,31]$. Using these values the predicted interface rate constant $\xi=-0.395 \mu \mathrm{m} / \mathrm{s}$ was calculated from Equation 8. This solidification rate is significantly less than the critical interface velocity $(16-400 \mu \mathrm{m} / \mathrm{s})$ required to engulf dispersed particle during solidification [26]. Li et al. [21] suggested that particle segregation tendency is dependent on the relationship between the liquid film width produced at the bonding temperature, particle diameter and inter-particle spacing. When the liquid film width is large enough that sufficient particulate material is contained in the melt, particles will be pushed ahead of the solidifying liquid-solid interface resulting in particle segregation at the bond-line. However if the liquid film width is less than some critical value, segregation should not occur. WDS analysis across the joint zone as a function of bonding time indicated that the Ni volume at the joint center varied between $3.67 \mathrm{wt} \%$ after 1 minute and 0.15 vol. $\%$ after 30 minutes bonding time. The relationship between the width of segregated region and the maximum liquid width that formed during bonding was determined by using equation 12 . 


$$
S_{s z}=W_{\max }\left[\frac{\delta_{p}+\chi_{2}}{\delta_{p}+\chi_{1}}\right]
$$

Where $\delta_{\mathrm{p}}$ is the average particle size, $\chi_{1}$ is the inter-particle spacing in the as received MMC and $\chi_{2}$ is the inter-particle spacing after bonding at the joint. By substituting $\delta_{\mathrm{p}}=28 \mu \mathrm{m}$, $\chi_{1}=10 \mu \mathrm{m}$ and $\chi_{2}=0$ into Equation 6.3, the relationship between the width of the particle segregated zone and the maximum width of the eutectic liquid phase was found to be, $S_{s z}=0.74 \mathrm{~W}_{\max }$. This means that the width of the segregated zone is approximately $74 \%$ of the width of the maximum width of the eutectic liquid phase formed during bonding.

\section{Conclusion}

Transient liquid phase diffusion bonding of particle reinforced Al-6061 MMC using Ni$\mathrm{Al}_{2} \mathrm{O}_{3}$ interlayer was successfully achieved using nano-composite $\mathrm{Ni}-\mathrm{Al}_{2} \mathrm{O}_{3}$ coating. The results obtained from the spectroscopic analyses using WDS and XRD showed that $\mathrm{Ni}-\mathrm{Al}_{2} \mathrm{O}_{3}$ coating the bonding process can be characterized in four distinct stages: interfacial contact and solid-state diffusion, which resulted in the formation of three reaction layers promoted by the diffusion of nickel into the aluminum base metal. The second stage of the joining process was the formation of an Al-Ni-Si eutectic liquid at the bonding temperature. It is supported that the reaction layers formed within the joint melted to form a liquid phase, followed by dissolution of the base metal (third stage) as the liquid spread between the bonding surfaces through capillary action. The final stage of bonding involved isothermal solidification at the bonding temperature in which the diffusion of $\mathrm{Ni}$ into $\mathrm{Al}$ results in a change in the composition of the liquid phase leading to solidification.

The joint shear strength was studied as a function of bonding parameters, bonding time, bonding temperature, interlayer thickness and interlayer particle size. The results showed that the joint shear strength increased with increasing bonding time, bonding temperature and interlayer thickness. On the other hand the results showed that bond strength increased when the interlayer particle size was reduced from $500 \mathrm{~nm}$ to $50 \mathrm{~nm}$. The increase joint shear strength seen when $\mathrm{Ni}-\mathrm{Al}_{2} \mathrm{O}_{3}$ coating were used was attributed to the presence of highlydispersed nano-sized reinforcement particles in the joint region act to strengthen the joint region by Orowan bowing mechanism.

The results showed that an optimum joint strength of $144 \mathrm{MPa}$ can be achieved if the following bonding parameters are used: 30 minutes bonding time, $620^{\circ} \mathrm{C}$ bonding temperature, and $11 \mu \mathrm{m}$ thick $\mathrm{Ni}-\mathrm{Al}_{2} \mathrm{O}_{3}$ coating. Within the parameter ranges tested the bonding pressure had the lease effect on the joint shear strength of TLP bonded joints.

\section{Author details}

Kavian Cooke

Department of Mechanical Engineering, School of Engineering, University of Technology, Jamaica 


\section{References}

[1] W. D. Macdonald and T. W. Eager 'Transient Liquid Phase bonding processes' Minerals Metals and Joining Society, 1992, 93-101

[2] I. Tuah-Poku, M. Dollar and T. B. Massalski, 'A study of the transient Liquid phase bonding process applied to a Ag/Cu/Ag sandwich joint' Metall. Trans. A, 1988, 19 A, $675-686$

[3] Y. Zhou, W.F. Gale, and T.H. North Modelling of Transient Liquid. Phase Bonding, International Material Review, (1995) Vol. 40, No.5, pp 181-196

[4] ASTM E3 -01 (2008) Standard preparation for metallographic examination, ASTMInternational 100 Barr Harbor drive United States

[5] Z. Li, Y. Zhou, T.H. North,'Counteraction of particulate segregation during transient liquid-phase bonding of aluminum-based MMC material' Mater. Sci. 1995, 30, 10751082

[6] A.A. Shirzadi, E.R. Wallach, (1997) New approaches for transient liquid phase diffusion bonding of Aluminum based metal matrix composites, Material Science Technology Vol.13, pg: 135-142.

[7] Y. Z hou W. F. Gale, and T. H. North, Modeling of transient liquid phase bonding, International Mater. Rev., 1995, Vol. 40, No.5, 181-196.

[8] N. S. Bosco, F. W. Zok, Critical interlayer thickness for transient liquid phase bonding in the Cu-Sn system, Acta Materialia, 2004, Vol. 52. pg: 2965-2972.

[9] W. D. Macdonald and T.W. Eager, 'Transient liquid phase bonding processes' Minerals Metals and Joining Society, 1992, 93-101.

[10] J.R. Askew, J.F. Wilde and T.I. Khan, Transient liquid phase bonding of 2124 aluminum metal matrix composite, Mater. Sci. Tech. 1998, 14 920-924.

[11] R.F. Chen, Y.H. Zhao, Z.X. Shen, L.G. Dai, X.L. Zhang, R. Zhu, Study on the joint strength of $\mathrm{SiCp} / \mathrm{Al}$ metal-matrix composite by magnetron sputtering method, Mater. Sci. 2009, pp $628-629$

[12] A. Suzumura, and Y. Xing, Diffusion brazing of short $\mathrm{Al} 2 \mathrm{O} 3$ fiber reinforced aluminum composite. Mater. Trans., 1996, Vol. 37, pg: 1109-1115.

[13] T. Enjo, K. Ikeuchi, Y. Murakami, N. Suzuki, Diffusion bonding of aluminummagnesium-silicon series 6063 alloy reinforced with alumina short fibers, Trans. of JWRI, 1987, Vol.16, No. 2, pg: 285-92

[14] Y. Zhai, T.H. North and J. Serrato-Rrodrigues, Transient liquid-phase bonding of alumina and metal matrix composite base materials, Mater. Sc., 1997, Vol.32, pg;13931397.

[15] A. A. Shirzadi, E.R. Wallach, New approaches for transient liquid phase diffusion bonding of Aluminum based metal matrix composites, Mater. Sci. Tech., 1997, Vol.13, pg: 135-142.

[16] A. Urena, J.M. Gomez de Salazar, and M.D. Escalera, Diffusion bonding of and aluminum metal matrix composites Weld. J, 1997, Vol.76, Pg: 92-102.

[17] D.M Stefanescu, Science and engineering of casting solidification, Kluwer Academic/Plenum Publishers, New York (2002). 
[18] D.M. Stefanescu, F.R. Juretzko, B.K. Dhindaw, A. Catalina, S. Sen, P.A. Curreri, "Particle Engulfment and Pushing by Solidifying Interfaces: Part II, Microgravity Experiments and Theoretical Analysis" Metall. Mater. Trans. A, Vol. 29 (1998), pp; 1697.

[19] Z.W. Xu, J.C. Yan, G.H. Wu, X.L. Kong, S.Q. Yang, Interface structure and strength of ultrasonic vibration liquid-phase bonded joints of Al2O3p/6061Al composites Scripta Materialia, 2005, Vol. 53, pg: 835-839

[20] J.H. Huang, Y.L. Dong, Y. Wan, J.G. Zhang, G.A. Zhou, Reactive diffusion bonding of $\mathrm{SiCp} / \mathrm{Al}$ composites by insert layers of mixed powders, Mater. Sci. Tech., 2005, Vol. 21, pg: 1217-1221

[21] B. Wielage, I. Hoyer, S. Weis, Soldering aluminum matrix composites. Weld J 2007;86:67-70

[22] J. Yan, Z. Xu, L. Shi, X. Ma, S. Yang, Ultrasonic assisted fabrication of particle reinforced bonds joining aluminum metal matrix composites Mater Des. 32 (2011) 343-347

[23] K.O. Cooke, T.I. Khan, G.D. Oliver (2011) Nanostructure particle-reinforced transient liquid phase diffusion bonding; a comparative study, Metall. Mater. Trans. A, DOI: 10.1007/s11661-011-0663-6.

[24] K.O. Cooke, T.I. Khan, G.D. Oliver (2011) Transient liquid phase diffusion bonding Al6061 using nano-dispersed Ni coatings, Mater. Des. DOI: 10.1016/j.matdes.2011.04.051.

[25] W. Deqing, S. Ziyuan and K. Tangshan, Composite plating of hard chromium on aluminum substrate, Surface and Coatings Technology, 2005, Vol.191, pp:324- 329

[26] D.R. Gabe, Principles of metal surface treatment and protection, Anti-Corrosion Methods and Materials, Published by Pargamon Press, Oxford,1972,

[27] W.F. Gale and D.A. Butts, Transient liquid phase bonding Science and Technology, Journal of Welding and Joining, 2004, Vol. 9, No. 4, pp: 283-300.

[28] W.D. Zhuang and T.W. Eagar, Transient liquid-phase bonding using coated metal powders Welding Journal, 1997, Vol. 76, Issue 12, Pages 157-167.

[29] M.L. Kuntz, Y. Zhou, and S.F. Corbin, A study of transient liquid-phase bonding of Ag$\mathrm{Cu}$ using differential scanning calorimetry, Metallurgical and Materials transaction A, Vol. 37A, 2006, pp: 2493-2504.

[30] D.S. Duvall, W.A Owczarski, and D.F. Paulonis, TLP bonding: a new method of joining heat resisting alloys, Welding journal, Vol 53, No4. 1974, pp: 203-214

[31] W. F. Gale. and T. C. Totemeier 'Smithells Metals Reference Book', 8th Edn, 2004, Published by Elsevier

[32] K. Cooke, T. Khan and G. Oliver (2012) Critical interlayer thickness required for transient liquid phase bonding using nano-dispersed Ni coatings, submitted to Journal of Science and Technology of Welding and Joining Vol. 17 No. 1 page 22-31.

[33] K.O. Cooke, A Study of the Effect of Nanosized Particles on Transient Liquid Phase Diffusion Bonding Al6061 Metal-Matrix Composite (MMC) Using Ni/ $\mathrm{Al}_{2} \mathrm{O}_{3}$ Nanocomposite Interlayer, Metallurgical and Materials Transaction B, (2012) (accepted article) DOI: 10.1007/s11663-012-9643-5 
[34] Y.-L. Shen, E. Fishencord, N. Chawla, Correlating macrohardness and tensile behavior in discontinuously reinforced metal matrix composites Scripta. Materialia, Vol. 42, 2000, pp 427.

[35] Z.Y. Ma, Y.L. Li, Y. Liang, F. Zheng, J. Bi, S.C. Tjong, Nanometric Si3N4 particulatereinforced aluminum composite, Journal of Material Science and Engineering A 219 (1996) 229.

[36] I. Shao, P.M. Vereecken, C.L. Chien, P.C. Searson and R.C. Cammarata, Synthesis and characterization of particle-reinforced J Mater Res 17 (2002), pp. 1412-1418.

[37] L. Thilly, M. Véron , O. Ludwig, F. Lecouturier Deformation mechanism in high strength $\mathrm{Cu} / \mathrm{Nb}$ nano-composites Materials Science and Engineering A309-310 (2001) 510-513

[38] S.V. Kamat and M. Manoharan, Work hardening behaviour of alumina particulate reinforced 2024 aluminum alloy matrix composites, Journal of Composite Materials 1993, 27: 1714-1721 DOI: 10.1177/002199839302701801

[39] H. Nami, A. Halvaee and H. Adgi, Transient liquid phase diffusion bonding of $\mathrm{Al} / \mathrm{Mg} 2 \mathrm{Si}$ metal matrix composite, Materials and Design, 2011, doi:10.1016/j.matdes.2011.02.003

[40] G.A. Chadwick and P.J. Heath, Machining metal matrix composites Mater. 6/2 (1990), pp. 73-76.

[41] Z.Y. Ma, SC. Tjong, In situ ceramic particle-reinforced aluminum matrix composites fabricated by reaction pressing in the $\mathrm{TiO} 2$ (Ti)-Al-B (B2O3) systems Metallurgical Material Transaction 1997; 28(A):1931-42.

[42] S. C. Tjong, Novel nanoparticle-reinforced metal matrix composites with enhanced mechanical properties, Advanced Engineering Materials Volume 9, Issue 8, 2007

[43] S. F. Hassan, M. Gupta, “Development of high performance magnesium nanocomposites using solidification processing route Journal of Material Science and Technology, 2004, 20, 1383.

[44] N. Srikanth, S. F. Hassan, M. Gupta, Energy dissipation studies of Mg-based nanocomposites using an innovative circle-fit approach, Journal of Composite Material.2004, 38, 2037.

[45] Z. Zhang, D. L. Chen, Consideration of Orowan strengthening effect in particulatereinforced metal matrix nano-composites: A model for predicting their yield strengthScr. Mater. 2006, 54, 1321.

[46] K. W. Richter, K. Chandrasekaran and H. Ipser, The Al-Ni-Si phase diagram. Part II: phase equilibria between 33.3 and 66.7 at.\% Ni, Journal of Intermetallics, 12 (2004) 545554

[47] P. Nash, M.F. Singleton, J.L. Murray, in: P. Nash (Ed.), Phase Diagrams of Binary Nickel Alloys, ASM International, Materials Park, OH, 1991, pp. 3-11.

[48] G. Rog , G. Borchardt, M. Wellen, W. Lose, determination of the activities in the (Ni + $\mathrm{Al}$ ) alloys in the temperature range $870 \mathrm{~K}$ to $920 \mathrm{~K}$ by a solid-state galvanic cell using a CaF2 electrolyte J. Chem. Thermodynamics 35 (2003) 261-268 
[49] V. Raghavan, Al-Ni-Si (Aluminum-Nickel-Silicon) Phase diagram evaluations, Journal of Phase Equilibria and Diffusion, 2005, Vol. 26, pp:262-267

[50] E. Dmitry, G. Belov, N.A. Aksenov, and A. Andrey, (2005) Multicomponent Phase Diagrams : Applications for Commercial Aluminum Publisher: Elsevier Science

[51] C.W. Sinclair, 'Modelling transient liquid phase bonding in multi-component systems Journal of Phase equilibria, 1998, 20, No. 4, 